\title{
Time-resolved gas-phase kinetic, quantum chemical and RRKM studies of the reaction of silylene with 2,5-dihydrofuran
}

Article

Accepted Version

Becerra, R., Cannady, J. P., Pfrang, C. and Walsh, R. (2015) Time-resolved gas-phase kinetic, quantum chemical and RRKM studies of the reaction of silylene with 2,5-dihydrofuran. Journal of Physical Chemistry A, 119 (46). pp. 11241-11253. ISSN 1089-5639 doi: https://doi.org/10.1021/acs.jpca.5b07404 Available at https://centaur.reading.ac.uk/67271/

It is advisable to refer to the publisher's version if you intend to cite from the work. See Guidance on citing.

To link to this article DOI: http://dx.doi.org/10.1021/acs.jpca.5b07404

Publisher: ACS Publications

All outputs in CentAUR are protected by Intellectual Property Rights law, including copyright law. Copyright and IPR is retained by the creators or other copyright holders. Terms and conditions for use of this material are defined in the End User Agreement.

www.reading.ac.uk/centaur 
Central Archive at the University of Reading

Reading's research outputs online 


\title{
Time-resolved Gas-phase Kinetic, Quantum Chemical and RRKM Studies of the Reaction of Silylene with 2,5- Dihydrofuran
}

\author{
Rosa Becerra $*^{\dagger}$ J. Pat Cannady ${ }^{\ddagger}$ Christian Pfrang ${ }^{\S}$ and Robin Walsh ${ }^{\star \S}$ \\ †Instituto de Quimica-Fisica 'Rocasolano', C.S.I.C., C/Serrano 119, 28006 Madrid, Spain \\ ${ }^{\ddagger}$ Dow Corning Corporation, 2200 West Salzburg Road, Midland, Michigan, 48641 \\ ${ }^{\S}$ Department of Chemistry, University of Reading, Whiteknights, P.O. Box 224, Reading, \\ $R G 66 A D, U K$
}

\begin{abstract}
Time-resolved kinetic studies of silylene, $\mathrm{SiH}_{2}$, generated by laser flash photolysis of phenylsilane, have been carried out to obtain rate coefficients for its bimolecular reaction with 2,5-dihydrofuran (2,5-DHF). The reaction was studied in the gas phase over the pressure range 1-100 Torr in $\mathrm{SF}_{6}$ bath gas, at five temperatures in the range 296-598 K. The reaction showed pressure dependences characteristic of a third body assisted association. The second order rate coefficients obtained by RRKM-assisted extrapolation to the high pressure limits at each temperature, fitted the following Arrhenius equation where the error limits are single standard deviations:
\end{abstract}

$$
\log \left(k / \mathrm{cm}^{3} \text { molecule }^{-1} \mathrm{~s}^{-1}\right)=(-9.96 \pm 0.08)+\left(3.38 \pm 0.62 \mathrm{~kJ} \mathrm{~mol}^{-1}\right) / R T \ln 10
$$

End product analysis revealed no GC-identifiable product. Quantum chemical (ab initio) calculations indicate that reaction of $\mathrm{SiH}_{2}$ with 2,5-DHF can occur at both the double bond (to form a silirane) and the O-atom (to form a donor acceptor, zwitterionic complex) via barrierless processes. Further possible reaction steps have been explored, of which the only viable one appears to be decomposition of the O-complex to give 1,3-butadiene + 
silanone, although isomerisation of the silirane cannot be completely ruled out. The potential energy surface for $\mathrm{SiH}_{2}+2,5$-DHF is consistent with that of $\mathrm{SiH}_{2}$ with $\mathrm{Me}_{2} \mathrm{O}$, and with that of $\mathrm{SiH}_{2}$ with cis-but-2-ene, the simplest reference reactions.

RRKM calculations incorporating reaction at both $\pi$ - and O-atom sites, can be made to fit the experimental rate coefficient pressure dependence curves at 296-476 K, giving values for $k^{\infty}(\pi)$ and $k^{\infty}(\mathrm{O})$ which indicate the latter is larger in magnitude at all temperatures, in contrast to values from individual model reactions. This unexpected result suggests that, in 2,5-DHF with its two different reaction sites, the O-atom exerts the more pronounced electrophilic attraction on the approaching silylene. Arrhenius parameters for the individual pathways have been obtained. The lack of a fit at $598 \mathrm{~K}$ is consistent with decomposition of the O-complex to give 1,3-butadiene + silanone. 


\section{INTRODUCTION}

Silylenes are important intermediates in silicon hydride and organosilicon chemistry. ${ }^{1-5}$ Their characteristic reactions include insertions into Si-H, Si-OR and O-H bonds and $\pi$-type additions across $\mathrm{C}=\mathrm{C}$ and $\mathrm{C} \equiv \mathrm{C}$ bonds. Many of the fine details of the mechanisms of these reactions have been revealed by time-resolved kinetic studies employing direct monitoring of silylenes. ${ }^{6-16}$ In recent times, much attention has been devoted to the preparation and properties of large silylenes, stabilised either by bulky substituents, or by being built into N-heterocyclic rings or with N-heterocyclic adducts. ${ }^{17-21}$ Nevertheless there still remains a need to uncover further details of the behaviour of the smaller, more reactive silylenes to establish a reactivity baseline.

In our laboratories we have undertaken gas-phase studies of the prototype silylene, $\mathrm{SiH}_{2}{ }^{6-8}$ These investigations have shown, inter alia, that it reacts rapidly with many chemical species at close to collision rates. Amongst these are the reactions of $\mathrm{SiH}_{2}$ with propene and isobutene $e^{22}$ ( $\pi$-type additions which form siliranes) and with cyclic ethers which proceed via the intermediacy of donor acceptor complexes with zwitterionic character. ${ }^{23}$ Both types of reaction show pressure-dependent second order kinetics consistent with third-body assisted association mechanisms. Both have been modelled by Rice-Ramsperger-Kassel-Marcus (RRKM) theory ${ }^{24}$ which not only fitted the pressure dependences but also revealed the magnitudes of the association (binding) enthalpies. In the case of the reactions of $\mathrm{SiH}_{2}$ with $\mathrm{C}_{3} \mathrm{H}_{6}$ and $i-\mathrm{C}_{4} \mathrm{H}_{8}{ }^{22}$ these were 176 and $165 \mathrm{~kJ} \mathrm{~mol}^{-1}$ respectively, values closely matched by quantum chemical (G2) calculations. In the case of the reaction of $\mathrm{SiH}_{2}$ with cyclo- $\mathrm{C}_{4} \mathrm{H}_{8} \mathrm{O}$ (tetrahydrofuran) ${ }^{23}$ this was $92 \mathrm{~kJ} \mathrm{~mol}^{-1}$ which was in good agreement with G3 calculations. At the present time, experiments of this kind remain the only available approach for checking and verifying theoretical values for these energies. 
Because many potential substrates for silylene reactions contain more than one site of reactivity, we thought it would be valuable to investigate the reaction of $\mathrm{SiH}_{2}$ with such a species. The reason for such a study is to discover whether reaction rates at each site turn out to be additive. For this purpose we chose 2,5-dihydrofuran, a molecule containing both a $\pi$-bond and an O-donor site. This also has the advantage that it closely resembles the model reactions which we have already investigated. ${ }^{22,23}$ This particular reaction has not been previously studied, either experimentally or theoretically.

\section{EXPERIMENTAL SECTION}

Equipment, Chemicals and Method. The apparatus and equipment for these studies have been described in detail previously. ${ }^{25}$ Only essential and brief details are therefore included here. $\mathrm{SiH}_{2}$ was produced by the $193 \mathrm{~nm}$ flash photolysis of phenylsilane $\left(\mathrm{PhSiH}_{3}\right)$ using a Coherent Compex 100 exciplex laser. Photolysis pulses (beam cross section $4 \mathrm{~cm} \times 1 \mathrm{~cm}$ ) were fired into a variable temperature quartz reaction vessel with demountable windows, at right angles to its main axis. $\mathrm{SiH}_{2}$ concentrations were monitored in real time by means of a Coherent 699-21 single-mode dye laser pumped by an Innova 90-5 Argon ion laser and operating with Rhodamine 6G. The monitoring laser beam was multipassed 36 times along the vessel axis, through the reaction zone, to give an effective path length of $1.5 \mathrm{~m}$. A portion of the monitoring beam was split off before entering the vessel for reference purposes. The monitoring laser was tuned to $17259.50 \mathrm{~cm}^{-}$ 1 , corresponding to the known ${ }^{\mathrm{R}} Q_{0, \mathrm{~J}}$ (5) strong rotational transition ${ }^{25,26}$ in the $\mathrm{SiH}_{2}$ $\widetilde{A}^{1} \mathrm{~B}_{1}(0,2,0) \leftarrow \widetilde{X}^{1} \mathrm{~A}_{1}(0,0,0)$ vibronic absorption band. Light signals were measured by a dual photodiode/differential amplifier combination and signal decays were stored in a transient recorder (Datalab DL910) interfaced to a BBC microcomputer. This was used to average the decays of between 5 and 15 photolysis laser shots (at a repetition rate of 0.5 or 
$1 \mathrm{~Hz}$ ). The averaged decay traces were processed by fitting the data to an exponential form using a non-linear least squares package. This analysis provided the values for firstorder rate coefficients, $k_{\text {obs }}$, for removal of $\mathrm{SiH}_{2}$ in the presence of known partial pressures of substrate gas.

Gas mixtures for photolysis were made up, containing between 1.4 and 5.3 mTorr of $\mathrm{PhSiH}_{3}$, variable pressures of substrate and inert diluent $\left(\mathrm{SF}_{6}\right)$ to total pressures of between 1 and 100 Torr $^{\dagger}$. The pressures of substrate $(2,5-\mathrm{DHF})$ were in the range $0-450 \mathrm{mTorr}$. Pressures were measured by capacitance manometers (MKS, Baratron). All gases used in this work were frozen and rigorously pumped to remove any residual air prior to use. $\mathrm{PhSiH}_{3}(99.9 \%)$ was obtained from Ventron-Alfa (Petrarch). 2,5-DHF was from BDH (99.5\%). Sulfur hexafluoride, $\mathrm{SF}_{6}$, (no GC-detectable impurities) was from Cambrian Gases. GC purity checks were carried out with a $3 \mathrm{~m}$ silicone oil column (OV101) operated at $50^{\circ} \mathrm{C} . \mathrm{N}_{2}$ was used as carrier gas and detection was by FID. Detection limits for impurity peaks were better than $0.1 \%$ of the principal component.

2,5-DHF shows a weak absorption at $193 \mathrm{~nm}$ and in preliminary experiments, it was found by gas chromatographic (GC) analysis, that decomposition of a few percent occurred under the conditions of these studies. Without a longer wavelength absorbing precursor for $\mathrm{SiH}_{2}$ we were unable to avoid this problem. The consequences of this are considered in the results section.

Quantum chemical (ab initio) calculations. The Gaussian-3 (G3) method ${ }^{27}$ was employed to calculate the energies of reactants, products and suspected intermediate species, since it has been shown to provide values within chemical accuracy $( \pm 4 \mathrm{~kJ}$ $\mathrm{mol}^{-1}$ ) for a large range of compounds containing first and second row elements. G3 is a composite technique in which a series of defined ab initio molecular orbital calculations

${ }^{\dagger} 1$ Torr $=133.3 \mathrm{Nm}^{-2}$ 
are performed to arrive at a total energy for a given molecular species. The first stage is calculation of an equilibrium geometry structure. This is then used for a series of single point energy calculations at higher levels of theory which are combined in an additive manner to give the final result.

Structures were initially optimized at the HF/6-31G(d) level which was used to obtain frequencies and thereby zero point energies (following correction by the factor 0.8929). Structures were then refined at the MP2=Full/6-31G(d) level. This level has been found to give the best compromise between accuracy and computational requirements (cpu times). ${ }^{27}$ Stable structures, corresponding to energy minima, were identified by possessing no negative eigenvalues of the Hessian matrix, whilst transition states were identified by having one and only one negative eigenvalue. The Cartesian co-ordinates of all stable minima and transition states are given in the supporting information.

To reach final energies, values at MP2=Full/6-31G(d) geometry were corrected additively by four single point energy determinations, viz: QCISD(T)/6-31G(d), MP4/6$31+\mathrm{G}(\mathrm{d}), \mathrm{MP} 4 / 6-31 \mathrm{G}(2 \mathrm{df}, \mathrm{p})$ and MP2=full/G3large, and the values were combined according to the G3 procedure. ${ }^{27}$ This applies equally to stable species as to transition states. The only procedural difference for transition states was the requirement to refine to structures with a single energy maximum. This occasionally caused problems when the transition state structure was less easy to visualise. In such cases, the problem was solved by modifying the initial structure. The identities of the transition state structures were verified by calculation of Intrinsic Reaction Co-ordinates ${ }^{28}$ (IRC) at the MP2=Full/631G(d) level. Reaction barriers were calculated as differences in G3 enthalpies at 298.15 $\mathrm{K}$ (quoted simply as $\Delta H^{0}$ in the Tables and Figures of results). $\Delta G^{0}$ values were also recorded. 
The electronic structure calculations were performed initially with the Gaussian 98, then with the Gaussian 03 and finally the Gaussian 09 software packages. ${ }^{29}$ Comparisons showed negligible differences (no more than $2 \mathrm{~kJ} \mathrm{~mol}^{-1}$, for $\Delta H^{\circ}$ for a given species)

\section{RESULTS}

Kinetic Measurements. It was independently verified during preliminary experiments that, in a given reaction mixture, $k_{\mathrm{obs}}$ values were not dependent on the exciplex laser energy $(50-70 \mathrm{~mJ} /$ pulse routine variation) or number of photolysis shots. Because static gas mixtures were used, tests with up to 10 shots were carried out. The constancy of $k_{\text {obs }}$ (five shot averages) showed no effective depletion of reactants in any of the systems. Higher pressures of precursor were required at the higher temperatures because signal intensities decreased with increasing temperature. However, for the purposes of rate coefficient measurement at a given temperature the precursor pressure was kept constant to ensure a fixed (but fairly small) contribution to $k_{\mathrm{obs}}$ values. A series of experiments were done at five temperatures in the range 296-598 K. At each temperature, a number of runs (at least eight) at different 2,5-DHF partial pressures were carried out. The results of these experiments are shown in Figure 1, which demonstrates the linear dependence of $k_{\mathrm{obs}}$ on [2,5-DHF], as expected for second-order kinetics. The second order rate coefficients, $k$, obtained by least-squares fitting to these plots, are given in Table 1. The error limits are single standard deviations. The total pressure in these experiments was 10 Torr maintained by addition of $\mathrm{SF}_{6}$. Figure 2 shows an Arrhenius plot of the rate coefficients. The resulting equation is:

$$
\log \left(k / \mathrm{cm}^{3} \text { molecule } \mathrm{s}^{-1}\right)=(-11.37 \pm 0.14)+\left(10.04 \pm 1.01 \mathrm{~kJ} \mathrm{~mol}^{-1}\right) / R T \ln 10
$$

Uncertainties are again quoted as single standard deviations. 
In addition, at each temperature of study, another series of runs was carried out in which total pressures were varied by addition of $\mathrm{SF}_{6}$ within the range 1-100 Torr, in order to investigate the dependences of the rate coefficients on total pressure. The data were obtained in the same way as those at 10 Torr, although in these experiments only four or five substrate partial pressures were tried at each total pressure (since second order behaviour was established at 10 Torr). The pressure range was limited by practical considerations. Above ca 100 Torr transient signals became too small to measure reliably and below 1 Torr, pressure measurement uncertainties became significant. The variation of these rate coefficients with pressure is plotted in Figure 3, using log-log scales for convenience. As can be seen the rate coefficients show significant pressure dependence. This has been modelled by RRKM theory ${ }^{24}$ (see later) and the fits shown are the best obtained. The values for the high pressure limiting rate coefficients, also shown in Table 1, have additional uncertainties related to this fitting and are necessarily greater than those at 10 Torr. Figure 2 shows an Arrhenius plot of the rate coefficients obtained at the high pressure (infinite) limiting value as well as those obtained at 10 Torr. A linear least squares fit to the infinite pressure values corresponds to the Arrhenius equation below, where the uncertainties are again single standard deviations:

$$
\log \left(k^{*} / \mathrm{cm}^{3} \text { molecule } \mathrm{s}^{-1}\right)=(-9.96 \pm 0.08)+\left(3.38 \pm 0.62 \mathrm{~kJ} \mathrm{~mol}^{-1}\right) / R T \ln 10
$$

While the uncertainties involved in the use of extrapolated values are clearly greater than those obtained within the range of direct measurement, the use of RRKM theory to assist extrapolation keeps these to a minimum. Thus we would estimate that these Arrhenius parameters may have maximum uncertainties of $\pm 0.2\left(\log A^{\star}\right)$ and $\pm 1.5 \mathrm{~kJ} \mathrm{~mol}^{-1}\left(E_{\mathrm{a}}\right)$.

End Product Analyses. These could only be carried out for experiments at room temperature. A mixture of 0.7 Torr of $\mathrm{PhSiH}_{3}$ and 1.20 Torr of 2,5-DHF was subjected to 100 shots at $193 \mathrm{~nm}$ laser radiation (65mJ/pulse) and then analysed by GC (Silicon oil 
column at $323 \mathrm{~K}$ ). Under these conditions no major chromatographic peak eluting between 2,5-DHF itself and benzene (decomposition product of $\mathrm{PhSiH}_{3}$ ) was observed. Small amounts of 1,3-butadiene were detected, but a blank run with 2,5-DHF alone formed similar small amounts of 1,3-butadiene and we conclude that there is no evidence for significant butadiene formation as a product of $\mathrm{SiH}_{2}+2,5-\mathrm{DHF}$ at $296 \mathrm{~K}$. This suggests that stable end products were not formed in this reaction, at least not at room temperature. The total extent of decomposition of $2,5-\mathrm{DHF}$ in the blank ran was ca $0.5 \%$ per laser shot.

Quantum chemical (ab initio) calculations. An initial set of calculations ${ }^{30}$ revealed, apart from the reactant species $\left(\mathrm{SiH}_{2}+2,5\right.$-dihydrofuran $), 11$ other minima and 10 transition states (TS1-9). The minima comprise 3 molecular complexes (2,5DHF $\cdot \mathrm{SiH}_{2}, 1,3-\mathrm{C}_{4} \mathrm{H}_{6} \cdot \mathrm{OSiH}_{2}$ and vinyloxirane $\cdot \cdot \mathrm{SiH}_{2}$ ), four closed shell and valencesaturated molecular species (3-oxa-6-sila-bicyclo[3,1,0]hexane (syn and anti forms), 2sila-3,6-dihydropyran and 3-vinylsiloxetane), two closed shell ${ }^{31}$ but valence-unsaturated silylenes, cis-but-2-enoxysilylene and but-3-enoxysilylene and the molecular pairs, 1,3butadiene + silanone and $\mathrm{SiH}_{2}+$ vinyloxirane. Most of these lie lower in enthalpy than the reactants and are therefore potential end products. However two of them (vinyloxirane $\cdot \mathrm{SiH}_{2}$ and $\mathrm{SiH}_{2}+$ vinyloxirane) are higher in enthalpy and are only included for completeness. Total enthalpies (at 298K) and enthalpy and free energy values for all structures relative to $\mathrm{SiH}_{2}+2,5-\mathrm{DHF}$ are shown in Table 2 . The analysis that follows is largely framed in terms of enthalpy surfaces, because they are virtually independent of temperature.

The minima and transition states linking these species are shown on the PESs in Figures 4 and 5: not included in the figures are the complexes $\mathrm{C}_{4} \mathrm{H}_{6} \cdot{ }^{\circ} \mathrm{OSiH}_{2}$ and vinyloxirane $\cdot \mathrm{SiH}_{2}$. The first because it does not appear to be involved in the pathways leading to $1,3-\mathrm{C}_{4} \mathrm{H}_{6}+\mathrm{H}_{2} \mathrm{SiO}$ and the second because it is endothermic with respect to 
the reactants and moreover has a high barrier (TS9) to its formation from 3vinylsiloxetane. Also not shown are the potential product pair, $\mathrm{SiH}_{2}+$ vinyloxirane because they are even more endothermic than vinyloxirane $\cdot \mathrm{SiH}_{2}$. A conformational transition state of $\mathrm{DHF} \cdot \mathrm{SiH}_{2}$ is also not included to avoid cluttering the diagram (Figure 5). Although the structures of most of these species are shown in these two figures, complete and larger diagrams are included in the supporting information.

G3 calculations were carried out on all structures which appeared reasonable to us. The surface indicates that reaction can take place by one or both of two barrierless pathways to form the O-donor (zwitterionic) complex, 2,5-DHF $\cdot \mathrm{SiH}_{2}$, and/or the double bond- or $\pi$ - adduct, 3-oxa-6-sila-bicyclo[3,1,0]hexane-syn, which also has an anti-form which is slightly less stable. Both are exothermic processes, downhill in enthalpy by 84 and 189 (175) $\mathrm{kJ} \mathrm{mol}^{-1}$, respectively. Further reaction may in principle proceed from either adduct. We consider first the $\pi$-adduct. The pathways we initially investigated ${ }^{30}$ are shown in Figure 4. Only the more stable syn-form is depicted, since the anti-form is readily converted to it, and may simply be regarded as a conformer. Exploration of its possible further reactions gave us two transition states, TS1 and TS2, both positive in enthalpy relative to reactants. TS1 $\left(+31 \mathrm{~kJ} \mathrm{~mol}^{-1}\right)$ leads to 3-vinylsiloxetane via a process involving $\mathrm{Si}$ to $\mathrm{O}$ migration simultaneous with breaking of the silirane ring and one of the C-O bonds. TS2 $\left(+98 \mathrm{~kJ} \mathrm{~mol}^{-1}\right)$ leads to butadiene and silanone via a coupling of Si and $\mathrm{O}$ and direct elimination of $\mathrm{H}_{2} \mathrm{Si}=\mathrm{O}$. With the complexity of both of these processes it is hardly surprising that they have high barriers. Subsequent to this ${ }^{30,32}$ we have discovered two other low barrier and therefore potentially energetically viable reaction pathways for decomposition of 3-oxa-6-sila-bicyclo[3,1,0]hexane, details of which are given in the supporting information. 
For the O-adduct pathway, via the $2,5-\mathrm{DHF} \cdot \mathrm{SiH}_{2}$ complex, we have identified two potential pathways for further reaction, shown in Figure 5. The first involves a ring expansion via TS3 to form 2-sila-3,6-dihydropyran, requiring an insertion of the $\mathrm{SiH}_{2}$ group into a C-O of the DHF ring. However this channel has to surmount a barrier of 54 $\mathrm{kJ} \mathrm{mol}^{-1}$ relative to reactants, and is therefore unviable. The second pathway involves a decomposition via TS4 $\left(-67 \mathrm{~kJ} \mathrm{~mol}^{-1}\right)$ requiring the breaking of both $\mathrm{C}-\mathrm{O}$ bonds and the extrusion of silanone $\left(\mathrm{H}_{2} \mathrm{Si}=\mathrm{O}\right)$. From the structure of TS4 it appears that the breaking of the first $\mathrm{C}-\mathrm{O}$ bond is rate determining. However the important point is that the low enthalpy value makes this a viable possibility. The same conclusion may be reached in free energy terms (Table 2). Furthermore this does not alter significantly with temperature. $^{33}$ The structure of TS4, with one C-O bond largely intact, led us to think that there might be a related pathway (from TS4) leading to 2-sila-3,6-dihydropyran by ring closure by means of $\mathrm{Si}-\mathrm{C}$ bond formation. However despite searching numerous structures closely related to TS4, no such new transition state or pathway could be found.

Although they do not appear to be part of the mechanism of this reaction, we have included in Figure 5 several other species and pathways, all of which lie lower in enthalpy than the reactants. These all involve rearrangements of 2-sila-3,6-dihydropyran and would become viable if the latter could be formed by a pathway undetected by us. The step with the lowest enthalpy barrier, is a retro Diels-Alder reaction leading directly to butadiene + silanone, via TS5 $\left(-208 \mathrm{~kJ} \mathrm{~mol}^{-1}\right)$. The fact that the enthalpy of TS5 is below that of the products at G3 level is almost certainly an artefact of the calculation since the IRC calculation (run at the MP2=Full/6-31G(d) level), confirms that it connects the species in question. The next lowest enthalpy barrier, that of TS6, $\left(-168 \mathrm{~kJ} \mathrm{~mol}^{-1}\right)$, corresponds to a 1,3 silyl shift process leading to 3-vinylsiloxetane. The remaining two 
pathways occur via silylene extrusion processes, the reverse reactions of insertion into $\mathrm{C}-\mathrm{H}$ bonds, requiring higher barriers than that of TS6. But-3-enoxysilylene, is formed via TS7 (-146 $\left.\mathrm{kJ} \mathrm{mol}^{-1}\right)$ and cis-but-2-enoxysilylene occurs via TS8a (-103 $\left.\mathrm{kJ} \mathrm{mol}^{-1}\right)$. A second route to this latter product via the higher enthalpy TS8b $\left(-98 \mathrm{~kJ} \mathrm{~mol}^{-1}\right)$ is not shown. Of course these last three steps, even if they did occur, would be highly reversible, since they are endothermic relative to 2-sila-3,6-dihydropyran.

For reference purposes we have also carried out G3 calculations on the reactions of $\mathrm{SiH}_{2}$ with dimethyl ether $\left(\mathrm{Me}_{2} \mathrm{O}\right)$. The results of these calculations are given in Table 13 and the potential energy surface for $\mathrm{C}_{2} \mathrm{H}_{8} \mathrm{SiO}\left(\mathrm{SiH}_{2}+\mathrm{Me}_{2} \mathrm{O}\right)$ is shown in Figure 7. These are considered further in the discussion section. Further G3 calculations on the reference reaction of $\mathrm{SiH}_{2}$ with cis-but-2-ene are included in the supporting information.

RRKM calculations. In order to judge whether the observed pressure dependences are consistent with the likely association processes of $\mathrm{SiH}_{2}$ with 2,5-DHF we have undertaken RRKM calculations ${ }^{24}$ of the reverse decomposition processes of the complexes formed. A further complication of this reaction system is the possible decomposition of the O-donor complex to give butadiene (and silanone). A general mechanism is shown in scheme (1) below. If the mechanism involves only steps (a) and (-a) and collisional stabilisation, then RRKM theory should be able to provide a fit. But if step (b) is occurring then this will not be the case.

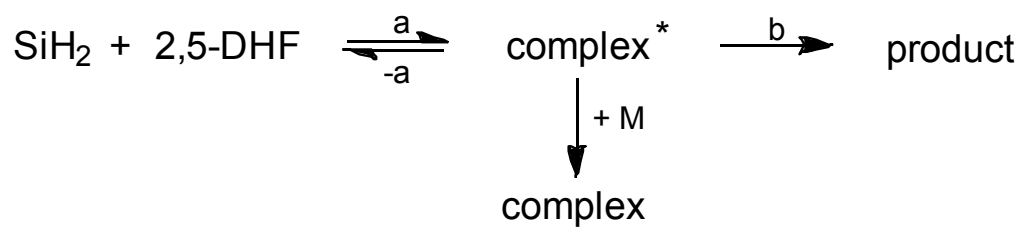

\section{Scheme 1}

The two principal uncertainties in modelling this scheme were the relative proportions of addition occurring via the $\pi$ - and O-complexes and the extent of reaction 
(if any) to form butadiene and silanone. Before beginning more precise calculations on the present system, we proceeded empirically by dividing up the overall process (rate coefficients) into contributions from each pathway according to the model reactions $\mathrm{SiH}_{2}+\mathrm{i}-\mathrm{C}_{4} \mathrm{H}_{8}{ }^{22}$ and $\mathrm{SiH}_{2}+\mathrm{THF}^{23}$ for which rate coefficients are already known. This required values for the high pressure limiting rate coefficients, $k^{\infty}$, in the present system, which, ideally, are best obtained by modelling. This "chicken-and-egg" problem was solved as follows. RRKM curves of the pressure dependence were generated (see below) based on a loose transition state model (corresponding to $\log \left(A / \mathrm{s}^{-1}\right)=16.88$ ) and a variable critical energy, $E_{0}$, designed to fit optimally the curvature of the experimental $P$ dependence curves of Figure 3 at each temperature. These yielded the values for $k^{\infty}$ shown in Table 3, although they also showed that the optimal $E_{\mathrm{o}}$ values varied between $125 \mathrm{~kJ} \mathrm{~mol}^{-1}$ (at 296K) and $165 \mathrm{~kJ} \mathrm{~mol}^{-1}$ (at 598K). This already indicates that the pressure dependence must be caused by more than one process. The next stage was to compare these $k^{\infty}$ values with the composite, $k^{\infty}\left(\mathrm{i}-\mathrm{C}_{4} \mathrm{H}_{8}\right)+k^{\infty}(\mathrm{THF})$, estimated from the model reactions ${ }^{22,23}$ for these processes at each temperature of study of the reaction here. The values are shown in Table 3 and indicate that while the composite is close in magnitude to the experimental sum, it is actually larger by between 20 and $50 \%$. Estimates for $k^{\infty}(\pi)$ and $k^{\infty}(\mathrm{O})$, the contributing rate coefficients for each individual process in the present scheme, were made by scaling $k^{\infty}\left(\mathrm{i}-\mathrm{C}_{4} \mathrm{H}_{8}\right)$ and $k^{\infty}(\mathrm{THF})$ by the appropriate reduction factor at each temperature. The resulting values are also shown in Table 3 (initial values). There it can be seen that, while $k^{\infty}(\pi)$ and $k^{\infty}(\mathrm{O})$ are of the same order of magnitude, $k^{\infty}(\mathrm{O})$ decreases with temperature more rapidly than $k^{\infty}(\pi)$. The Arrhenius parameters for these estimated rate coefficients were as follows: log $\left(A^{\infty}(\pi) / \mathrm{cm}^{3}\right.$ molecule $\left.\mathrm{s}^{-1}\right)=-9.99 \pm 0.10, E_{\mathrm{a}}(\pi)=-2.09 \pm 0.74 \mathrm{~kJ} \mathrm{~mol}^{-1} ; \log \left(A^{\infty}(\mathrm{O}) / \mathrm{cm}^{3}\right.$ 
molecule $\left.\mathrm{s}^{-1}\right)=-10.69 \pm 0.08, E_{\mathrm{a}}(\mathrm{O})=-5.60 \pm 0.60 \mathrm{~kJ} \mathrm{~mol}^{-1}$. These values are necessary for the ensuing calculations.

The RRKM calculations for each channel were then carried out in combination with a collisional deactivation model (also called the master equation method) in similar manner to those of previous work. ${ }^{22,23,25,34-51}$ The procedure was as follows. First $A$ factors for the decomposition of each of the $\pi$ - and O-complexes were calculated by use of the microscopic reversibility relationship, $\ln \left(A_{-\mathrm{a}} / A_{\mathrm{a}}\right)=\Delta S_{\text {-a,a }} \mathrm{o} / R$, where $A_{\text {-a }}$ and $A_{\mathrm{a}}$ are the decomposition and combination $A$ factors (ie $A_{\text {-a }}$ is what is required and $A_{\mathrm{a}}$ is the experimental, infinite pressure, value measured here (see above)) and $\Delta S_{-\mathrm{a}, \mathrm{a}}{ }^{\mathrm{o}}$ is the entropy change. Some details of this process are discussed in the supporting information. The values for $\Delta S_{-\mathrm{a}, \mathrm{a}}$ o were approximated by assuming the same values as for the dissociation of the model $\pi$ - and O-complexes. The data for these are shown in Table 4. Uncertainties in entropy values derived in this way are unlikely to exceed $\pm 4 \mathrm{~J} \mathrm{~K}^{-1} \mathrm{~mol}^{-1}$ and therefore values of $\log \left(A_{-\mathrm{a}} / \mathrm{s}^{-1}\right)$ should be good to \pm 0.2 .

Vibrational assignments for the $\pi$ - and O-complexes were obtained by combining those of $2,5-\mathrm{DHF}^{52}$ with those obtained for structurally similar $\mathrm{SiH}_{2}$ adducts from earlier work. ${ }^{23,34-51,53}$.Vibrational assignments of the transition states were obtained by the same procedure as previously ${ }^{22,23,25,34-51}$ based on adjustment of the vibrational wavenumbers of the adduct complexes to match the $A_{\text {-a }}$ values for their decompositions ${ }^{24}$ at each temperature, viz those of Table 4 . Although the values of $A_{\mathrm{a}}$ for each reaction were fixed, this has the effect of introducing variational character, since the derived wavenumber values are different at each temperature. Examples of the complex and transition state assignments for each reaction are shown in Tables 5 and 6 . The lists of specifically adjusted Transition State wavenumbers at each temperature are shown in Tables 7 and 8 . We have also assumed, as previously, that geometry changes between 
reactant and transition state do not lead to significant complications. In modelling the collisional deactivation process, we have used a weak collisional (stepladder) model, ${ }^{54}$ because there is overwhelming evidence against the strong collision assumption. ${ }^{24}$ The average energy removal parameter, $\langle\Delta E\rangle_{\text {down }}$, which determines the collision efficiencies, was taken as $12.0 \mathrm{~kJ} \mathrm{~mol}^{-1}\left(1000 \mathrm{~cm}^{-1}\right)$. This value for $\mathrm{SF}_{6}$ has been found to be the most appropriate, ie to give the best fits to experimental data in earlier studies, which included tests with other inert collider gases. ${ }^{25,35}$ Further details of the calculations are considered below.

At this point two ways of modelling the system were considered. Both methods involved readjusting the contributions of each pathway to try to match optimally the curvature and position of the pressure dependence plots. For each pathway, the extent of curvature is determined by the variation of $k / k^{\infty}$ with pressure and the position depends on $k^{\infty}$. The first method involved adjusting the $E_{0}(\pi)$ and $E_{0}(\mathrm{O})$ values by trial and error within reasonable limits, and for each selection carrying out the calculations described above to obtain $k / k^{\infty}$ as a function of pressure for both channels and at each temperature. To obtain the positions of these curves, $k^{\infty}$ values for each pathway were adjusted ${ }^{55}$ within the constraint of trying to keep the total $k^{\infty}(\pi)+k^{\infty}(\mathrm{O})$ at each temperature as close as possible to the initial value. Figure 3 shows the best fits we were able to obtain, using $E_{\mathrm{o}}(\pi)=148 \mathrm{~kJ} \mathrm{~mol}^{-1}$ and $E_{\mathrm{o}}(\mathrm{O})=80 \mathrm{~kJ} \mathrm{~mol}^{-1}$. More insight can be obtained, however, by examining Figure 6. This shows the individual pressure dependences of each pathway. It can be seen that O-pathway is much more pressure dependent than the $\pi$-pathway. This feature gets more pronounced as temperature increases. The $k^{\infty}$ values, necessary to obtain these fits are shown in Table 3. Compared with the initial values, $k^{\infty}(\mathrm{O})$ increases on average from 44 to $61 \%$ of the total and $k^{\infty}(\pi)$ decreases from 56 to $39 \%$ of the total, however the total values were mostly not changed. While the fits with experiment in 
Figure 3 are clearly not perfect, they are within reasonable bounds. Slightly revised Arrhenius parameters for $k^{\infty}(\pi)$ and $k^{\infty}(\mathrm{O})$ are included in the Tables 9 and 10. The activation energies can be used to obtain the values for $\Delta H^{\circ}(298 \mathrm{~K})$ via the microscopic reversibility relationship, $\Delta H^{\mathrm{o}}(298 \mathrm{~K})=E_{\mathrm{a}}-E_{\mathrm{a}}+R T$. Adjusted for thermal energy, the value for $E_{\mathrm{o}}(\pi)$ corresponds to $E_{\mathrm{a}}(\pi)=158 \mathrm{~kJ} \mathrm{~mol}^{-1}$ and the value for $E_{\mathrm{o}}(\mathrm{O})$ to $E_{\mathrm{-a}}(\mathrm{O})=$ $86 \mathrm{~kJ} \mathrm{~mol}^{-1}$. The values for $\Delta H^{\circ}(\pi, 298 \mathrm{~K})$ and $\Delta H^{\mathrm{o}}(\mathrm{O}, 298 \mathrm{~K})$ are respectively 164 and $92 \mathrm{~kJ} \mathrm{~mol}^{-1}$.

In the second approach to fitting, values of $E_{\mathrm{o}}(\pi)=186 \mathrm{~kJ} \mathrm{~mol}^{-1}$ and $E_{\mathrm{o}}(\mathrm{O})=84$ $\mathrm{kJ} \mathrm{mol}^{-1}$ from the quantum chemical calculations were used. The method of generating $k / k^{\infty}$ as a function of pressure for both channels and at each temperature combination was the same, but the method of combination of the pressure dependence curves for each pathway was different. The $k^{\infty}(\pi)$ and $k^{\infty}(\mathrm{O})$ values were chosen without constraint, to provide the best curvature to match experiment. The results of these calculations have a major difficulty. Although the fitting to experiment is not a lot worse than that of Figures 3 and 6 the required $k^{\infty}(\pi)$ and $k^{\infty}(\mathrm{O})$ values seem totally unreasonable. In particular $k^{\infty}(\mathrm{O})$ values are $c a 10^{-9} \mathrm{~cm}^{3}$ molecule $\mathrm{s}^{-1} \mathrm{~s}^{-1}$, viz an order-of-magnitude larger than the collision number and increase with temperature, unlike any analogous $\mathrm{SiH}_{2}$ reactions. $k^{\infty}(\pi)$ values are $5 \times 10^{-11} \mathrm{~cm}^{3}$ molecule $\mathrm{s}^{-1}$ about a factor of 4 smaller than expected (see Table 3). The results of these calculations are not shown here, but details can be found in the supporting information. No further RRKM calculations were attempted. The results are further commented on in the discussion.

\section{DISCUSSION}

General comments and rate coefficient comparisons. The lack of GC-detectable end products in this reaction indicates that any initially formed adducts, even if they last 
long enough in the reaction vessel, do not survive passage through a GC column. From previous studies, ${ }^{23,35,48,56}$ we know that this would apply to both siliranes ( $\pi$-adducts of the type formed here) and zwitterions (O-adducts). Thus despite the lack of concrete product information, past precedent strongly supports the initial steps in the mechanism proposed for this reaction

Although it was noted that 2,5-DHF undergoes photolysis to a small extent at 193 $\mathrm{nm}$, this does not affect the kinetic results obtained here. Most kinetic runs were done with 5 laser shots but even at 15 shots the most 2,5-DHF decomposition would have been $7.5 \%$. The constancy of $k_{\mathrm{obs}}$ values for $\mathrm{SiH}_{2}$ decay confirmed no significant depletion of 2,5DHF. Moreover the high values of the rate coefficients obtained for $\mathrm{SiH}_{2}+2,5-\mathrm{DHF}$, suggest that even if a small quantity of a photo-product were present and reacting rapidly with $\mathrm{SiH}_{2}$, it would be unlikely to distort the results. The main experimental purpose of the present work was to study the kinetics of the reaction of $\mathrm{SiH}_{2}$ with 2,5-DHF for the first time and to investigate the temperature and pressure dependences of the second-order rate coefficients. This has been accomplished. The reaction has been found to be pressure dependent and to have a negative temperature dependence, ie rate coefficients which decrease with increasing temperature. This is characteristic of most silylene association reactions. ${ }^{7-9,34-51}$ There is previous work on reactions of $\mathrm{SiH}_{2}$ with both alkenes and cyclicethers in the gas phase with which we can compare these results. ${ }^{22,23}$ Comparisons are tricky, however, because all reactions of this type are pressure dependent, and the true bimolecular rate coefficients are only obtainable by extrapolation to high pressures. In the present case this is further complicated by the necessity of dividing the reaction between two possible pathways. The issue is discussed in more detail below, but the rate coefficients, $k^{\infty}(\pi)$ and $k^{\infty}(\mathrm{O})$, obtained from the optimised fitting are shown in Table 3. A Lennard-Jones collision number estimate for this reaction at $296 \mathrm{~K}$ gives a value of $6.2 \times$ 
$10^{-10} \mathrm{~cm}^{3}$ molecule $\mathrm{s}^{-1} \mathrm{~s}^{-1}$ When compared with the total $k^{\infty}$, this corresponds to an efficiency of $71 \%$, well within the typical $70-90 \%$ of many silylene reactions ${ }^{23,48,49,51,58}$ but greater than that $(45 \%)$ for $\mathrm{SiH}_{2}+\mathrm{THF}^{23,57}$ It may be reasonably assumed that the existence of the $\pi$ pathway explains the greater efficiency of reaction of $\mathrm{SiH}_{2}$ with 2,5DHF compared with THF. The rate coefficients in Table 3 have been used to obtain the infinite pressure Arrhenius parameters shown in Tables 9 and 10. Because of the uncertainties of extrapolation, maximum error limits are given. The comparison with other reactions $22,23,34,35,59$ shows that while the Arrhenius parameters obtained for $\mathrm{SiH}_{2}+\mathrm{DHF}$ are reasonable close to those for similar reactions of $\mathrm{SiH}_{2}$, nevertheless the $A$ factor for the $\pi$-addition looks a little low while that for the O-addition looks a little high. Likewise, $E_{\mathrm{a}}(\pi)$ looks a little too negative, and $E_{\mathrm{a}}(\mathrm{O})$ looks not quite negative enough. It is possible that the uncertainties resulting from the fitting procedure are greater than indicated by these error limits.

The question posed at the outset was whether these studies can show that the reactivities of silylene at each reaction site are additive. Examination of Table 3 shows that $k^{\infty}(\pi)$ values are ca $50 \%$ of those of $k^{\infty}\left(\mathrm{i}-\mathrm{C}_{4} \mathrm{H}_{8}\right)$ whereas $k^{\infty}(\mathrm{O})$ are close to $100 \%$ of $k^{\infty}(\mathrm{THF})$. Despite the uncertainties of the pressure-dependence fitting and selective choice of the reference processes, it is clear that the rate coefficients in this reaction system are comparable to those expected. However it is noteworthy that, whereas model reactions suggest that reaction of $\mathrm{SiH}_{2}$ with the $\pi$-system should be faster than that with an O-donor our results show that the reactivities for these sites in 2,5-DHF are the opposite way round. This indicates that, when the two reactivity centres are close together, the lone electron pairs of the O-donor site exert a slightly more powerful electrophilic attraction than the $\pi$ - electrons of the double bond. This suggests that, during the silylene approach to 2,5-DHF, it may experience the influence of the lone 
pair electrons at longer range, a novel conclusion which does not strike us as unreasonable.

Quantum chemical (ab initio) calculations. There have been no previous calculations on this reaction. But we can compare our results with those of closely related reaction systems. These are shown in Tables 11 and 12 and also Figure 7 (see also supporting information). In Table 11 the results for calculations of $\Delta H^{0}$ for formation of O-donor complexes are compared. For the reactions studied ${ }^{23,59-62}$ these fall in the range, -62 to $-99 \mathrm{~kJ} \mathrm{~mol}^{-1}$, although not all calculations are at the same level. For the most structurally similar reaction, $\mathrm{SiH}_{2}+\mathrm{THF}$, the value of $-94 \mathrm{~kJ} \mathrm{~mol}^{-1}$ differs by only $10 \mathrm{~kJ} \mathrm{~mol}^{-1}$ from that for the present system. The $\mathrm{G} 3$ value for $\mathrm{SiH}_{2}+2,5-\mathrm{DHF}$ is also close to that (expt) derived from the RRKM calculations. In Table 12 the results for the calculations of $\Delta H^{\mathrm{o}}$ for formation of the $\pi$-complexes, viz the silirane adducts, are compared. For the reactions studied, ${ }^{22,63-65}$ these fall in the range, -168 to $-203 \mathrm{~kJ}$ $\mathrm{mol}^{-1}$. Again these are not all at the same level. At G2/G3 level there is a wider spread of $\Delta H^{0}$ values for the $\pi$-complexes than for the O-donor complexes. For the most structurally similar reaction, $\mathrm{SiH}_{2}+$ cis but-2-ene, the value of $-169 \mathrm{~kJ} \mathrm{~mol}^{-1}$ differs by $20 \mathrm{~kJ} \mathrm{~mol}^{-1}$ from that of 3-oxa-6-sila-bicyclo[3,1,0]hexane in its more stable $s y n$ - form, although, interestingly only by $6 \mathrm{~kJ} \mathrm{~mol}^{-1}$ from that of the anti-form. Although the differences are not large, they reinforce the idea that silirane ring stabilities are particularly sensitive to substituent effects. ${ }^{22}$ The G3 $\Delta H^{0}$ values for both $\pi$-adducts of $\mathrm{SiH}_{2}+2,5-\mathrm{DHF}$ are somewhat higher than that (expt) derived from the RRKM calculations. It is possible that the experimental value is affected by the existence of another pathway (see supporting information).

Figure 7 shows the PE surface for the reference reaction of $\mathrm{SiH}_{2}+\mathrm{Me}_{2} \mathrm{O}$, the data for which are given Table 13. When compared with the enthalpies of Figure 5, a 
number of similarities are apparent. As well as the O-donor complex enthalpy mentioned above, the $\mathrm{SiH}_{2}$ insertion product, methyl methoxy-silane, $\mathrm{MeOSiH}_{2} \mathrm{Me}$, lies in a deep $\Delta H^{\mathrm{o}}$ well of similar magnitude to that of siladihydropyran relative to reactants, although the barrier to its formation, TS1r, is slightly higher than TS3. Silylene extrusion (reverse insertion) from $\mathrm{MeOSiH}_{2} \mathrm{Me}$ to form $\mathrm{MeOSiH}+\mathrm{CH}_{4}$, is also very close in overall $\Delta H^{0}$ to that of the analogous process from siladihydropyran, although, again, the barrier, TS2r, is higher than either TS7 or TS8a. The lower barriers of these processes on the $\mathrm{SiH}_{2}+2,5-\mathrm{DHF}$ surface probably reflect the fact that the key bonds involved are weakened by allylic stabilisation. Lastly, in Figure 7, the dissociation of the $\mathrm{Me}_{2} \mathrm{O} \cdot \mathrm{SiH}_{2}$ to form $\mathrm{MeOSiH}_{2}+\mathrm{Me}$, can be compared with the formation of TS4 from $2,5-\mathrm{DHF} \cdot \mathrm{SiH}_{2}$, since structurally this corresponds to $\mathrm{C}-\mathrm{O}$ bond breaking. The dissociation enthalpies are respectively 68 and $17 \mathrm{~kJ} \mathrm{~mol}^{-1}$, which, at first sight, look rather different. However, when probable allylic stabilisation ( $c a 46 \mathrm{~kJ} \mathrm{~mol}^{-1}{ }^{66}$ ) of TS4 is allowed for, these enthalpies look rather comparable. Thus the present G3 calculations show a high degree of consistency with those of the simplest reference reaction.

RRKM calculations and the mechanism. The method of fitting the pressure dependence used in this work was dictated by the two channel nature of this reaction, and the uncertainties were such that an empirical approach had to be adopted. In reality the resulting fit of the combined RRKM calculations for each pathway to the experimental pressure dependence curves shown in Figure 3 is fairly reasonable. The unavoidable restrictions imposed by the calculations, were (i) that $k(\mathrm{O})$ was much more pressure dependent than $k(\pi)$, and (ii) that $k(\pi)$ contributions must increase as temperature increases. The first point is illustrated by the relative contributions shown in Figure 7. The second point means that $k(\mathrm{O})$ at $598 \mathrm{~K}$ makes no contribution at all (unless it is 
artificially boosted by an order of magnitude). To match the experimental curvature at $598 \mathrm{~K}$ could only be achieved by setting the value of $E_{\mathrm{o}}(\pi)$ to the fairly low figure of 148 $\mathrm{kJ} \mathrm{mol}^{-1}$. Within these restrictions, adjustment of the $k^{\infty}$ values under the limitation of keeping as close as possible to the previously derived totals, gave the fits shown in Figure 3. Even with this, a fit to the $598 \mathrm{~K}$ curve was impossible, and the curvature at $476 \mathrm{~K}$ is poorly matched. We suggest that at these higher temperatures, another pathway may be intervening. There are two possibilities. The first is that the O-complex may be partially decomposing to butadiene and silanone, even though this does not occur at 296 $\mathrm{K}$. This is supported by the quantum chemical calculations, which gives a rather low enthalpy barrier for this process. The free energy barrier is also low enough to suggest reaction should occur. The second is that $\pi$-adduct (3-oxa-6-sila-bicyclo[3,1,0]hexanesyn) may be partially decomposing via the intermediacy of 3-tetrahydrofuranylsilylene to 2-sila-3,6-dihydropyran (see supporting information). Although this possibility, at first overlooked by us, has a low enthalpy barrier, its free energy barrier is positive suggesting it is unlikely to occur with ease at $296 \mathrm{~K}$. The uncertainties and complexity of the system prevent us, however, from including either of these channels in the modelling. The end-product analysis shows that neither butadiene nor 2-sila-3,6dihydropyran are formed at $296 \mathrm{~K}$ where the RRKM fit is good: this does not, however, rule out their formation at $598 \mathrm{~K}$ and $476 \mathrm{~K}$. Despite these problems with the modelling, the resulting values for $k^{\infty}$ from these fits seem reasonable in magnitude as discussed above.

The alternative approach, of fitting the pressure dependence curves, by keeping $E_{\mathrm{o}}$ for each channel fixed at the values from the quantum chemical calculations, was found to require unreasonable values for the high pressure limiting rate coefficients, $k^{\infty}$, and was 
therefore rejected, as described in the RRKM modelling section above and illustrated in the supporting information.

\section{ASSOCIATED CONTENT}

Supporting Information.: This contains details of the geometries of quantum chemically calculated structures, including their Cartesian coordinates, details of further calculations not included in the main mechanism, the microscopic reversibility relationship and its use for unit conversion and RRKM calculations not included in the main text. This material is available free of charge via the Internet at http://pubs.acs.org.

\section{ACKNOWLEDGEMENT}

R.B. thanks the Ministerio de Economia y Competitividad for support under Project CTQ2010-16402 and Royal Society of Chemistry for a journals grant.

\section{REFERENCES}

(1) Gaspar, P. P. in Reactive intermediates; Jones M. Jr., Moss, R. A., Eds.; WileyInterscience; N.Y., 1978; vol 1, p. 229.

(2) Gaspar, P.P. in Reactive intermediates, Jones M. Jr., Moss, R. A., Eds.; WileyInterscience; N.Y., 1981; vol 2, p. 335.

(3) Gaspar, P.P. in Reactive intermediates, Jones M. Jr., Moss, R. A., Eds.; WileyInterscience; N.Y., 1985, vol 3, p. 333.

(4) Gaspar, P. P.; West R. Silylenes. In The Chemistry of Organosilicon Compounds; Rappoport, Z., Apeloig, Y., Eds.; Wiley; Chichester, 1998; Vol. 2, Chapter 43, p. 2463.

(5) Tokitoh, N.; Ando, W. In Reactive Intermediate Chemistry, Moss, R. A., Platz, M. S., Jones, M. Jr., Eds.; Wiley \& Sons, NY, 2004, Chapter 14, p. 651. 
(6) Becerra, R.; Walsh, R. Kinetics \& mechanisms of silylene reactions: A prototype for gas-phase acid/base chemistry in Research in Chemical Kinetics, eds. R. G. Compton and G. M. Hancock, Elsevier, Amsterdam, 1995, Vol. 3, p. 263.

(7) Jasinski, J. M.; Becerra, R.; Walsh, R., Direct Kinetic Studies of Silicon Hydride Radicals in the Gas Phase. Chem. Rev. 1995, 95, 1203-1228.

(8) Becerra, R.; Walsh, R., What have we learnt about heavy carbenes through laser flash photolysis studies? Phys. Chem. Chem. Phys. 2007, 9, 2817-2835.

(9) Becerra, R.; Walsh, R., Kinetic studies of reactions of organosilylenes: what have they taught us? Dalton Trans. 2010, 39, 9217-9228.

(10) Moiseev, A. G.; Leigh, W. J., Diphenylsilylene. J. Am. Chem. Soc. 2006, 128, 14442-14443.

(11) Moiseev, A. G.; Leigh, W. J., Direct Detection of Diphenylsilylene and Tetraphenyldisilene in Solution. Organometallics 2007, 26, 6268-6276.

(12) Moiseev, A. G.; Leigh, W. J., Comparison of the Reactivities of Dimethylsilylene $\left(\mathrm{SiMe}_{2}\right)$ and Diphenylsilylene $\left(\mathrm{SiPh}_{2}\right)$ in Solution by Laser Flash Photolysis Methods. Organometallics 2007, 26, 6277-6289.

(13) Moiseev, A. G.; Coulais, E.; Leigh, W. J., Photochemistry of Cyclic Trisilanes: "Spring-Loaded" Precursors to Methylphenylsilylene. Chem. Eur. J. 2009, 15, 8485-8491.

(14) Leigh, W. J.; Kostina, S. S.; Bhattacharya, A.; Moiseev, A. G., Fast Kinetics Study of the Reactions of Transient Silylenes with Alcohols.Direct Detection of Silylene-Alcohol Complexes in Solution. Organometallics 2010, 29, 662-670.

(15) Kostina, S. S.; Leigh, W. J., Silanones and Silanethiones from the Reactions of Transient Silylenes with Oxiranes and Thiiranes in Solution. The Direct Detection of Diphenylsilanethione. J. Am. Chem. Soc. 2011, 133, 4377-4388.

(16) Kostina, S. S.; Singh, T.; Leigh, W. J., Electronic and Steric Effects on the Lewis Acidities of Transient Silylenes and Germylenes: Equilibrium Constants for Complexation with Chalcogen and Pnictogen Donors. Organometallics 2012, 31, 3755-3767.

(17) Mizubhata, Y.; Sasamori T.; Tokitoh, N., Stable Heavier Carbene Analogues. Chem Rev. 2009, 109, 3479-3511.

(18) Kira, M., New horizon of organosilicon chemistry. Dalton Trans 2010, 39, 91759175. 
(19) Lee, V. Y.; Sekiguchi, A. Heavy analogs of carbenes: Silylenes, Germylenes, Stannylenes and Plumbylenes in Organometallic compounds of low coordinate Si, $\mathrm{Ge}$, Sn and Pb: from Phantom species to stable compounds Wiley, Chichester, 2010, chapter 4, p. 139.

(20) Asay, M.; Jones, C.; Driess, M., N-Heterocyclic Carbene Analogues with LowValent Group 13 and Group 14 Elements: Syntheses, Structures, and Reactivities of a New Generation of Multitalented Ligands. Chem. Rev. 2011, 111, 354-396.

(21) Ghadwal, S. G.; Azhakar, R.; Roesky, H. W., Dichlorosilylene: A High Temperature Transient Species to an Indispensable Building Block. Acc. Chem. Res. 2013, 46, 444-456.

(22) Al-Rubaiey, N.; Carpenter, I. W.; Walsh, R.; Becerra R.; Gordon, M. S., Direct Gas-Phase Kinetic Studies of Silylene Addition Reactions: $\mathrm{SiH}_{2}+\mathrm{C}_{3} \mathrm{H}_{6}, \mathrm{SiH}_{2}+\mathrm{i}$ $\mathrm{C}_{4} \mathrm{H}_{8}$, and $\mathrm{SiMe}_{2}+\mathrm{C}_{2} \mathrm{H}_{4}$. The Effects of Methyl Substitution on Strain Energies in Siliranes. J. Phys. Chem. A 1998, 102, 8564-8572.

(23) Becerra, R.; Cannady, J. P.; Goulder, O.; Walsh, R., Time-Resolved Gas-Phase Kinetic, Quantum Chemical and RRKM Studies of Reactions of Silylene with Cyclic Ethers. J. Phys. Chem. A 2010, 114, 784-793.

(24) Holbrook, K. A.; Pilling, M. J.; Robertson S. H, Unimolecular Reactions, 2nd ed.; Wiley: Chichester, 1996.

(25) Becerra, R.; Frey, H. M.; Mason, B. P.; Walsh, R.; Gordon, M. S., Prototype $\mathrm{Si}-\mathrm{H}$ insertion reaction of silylene with silane. Absolute rate constants, temperature dependence, RRKM modelling and the potential-energy surface. $J$. Chem. Soc., Faraday Trans. 1995, 91, 2723-2732.

(26) Jasinski, J. M.; Chu, J. O., Absolute rate constants for the reaction of silylene with hydrogen, silane, and disilane. J. Chem. Phys. 1988, 88, 1678-1687.

(27) Curtiss, L. A.; Raghavachari, K.; Redfern, P. C.; Rassolov, V.; Pople, J. A., Gaussian-3 (G3) theory for molecules containing first and second-row atoms- J. Chem. Phys. 1998, 109, 7764-7776.

(28) Gonzales, C.; Schlegel, H. B., An improved algorithm for reaction path following. J. Chem. Phys. 1989, 90, 2154-2161.

(29) Frisch, M. J.; Trucks, G. W.; Schlegel, H. B.; Scuseria, G. E.; Robb, M. A.; Cheeseman, J. R.; Scalmani, G.; Barone, V.; Mennucci, B.; Petersson, G. A.; et al., Gaussian 09, Revision A. 02, Gaussian, Inc., Wallingford, CT, 2009.

(30) A further set were subsequently undertaken in response to a referee's request. 
(31) $\mathrm{SiH}_{2}$ is a ground state singlet species ${ }^{1,6}$ and most other silylenes are also singlets.

(32) Although the silirane ring, under thermal decomposition conditions ${ }^{22,35}$, appears to decompose uniquely by elimination of a silylene, ie the reverse of the $\pi$-type addition process, we extended our search for reaction pathways to include isomerisations initiated by $\mathrm{H}$-atom migration processes. To minimise the task a survey of such pathways for the model system, cis-2,3-dimethylsilirane, was carried out first followed by consideration of two potentially analogous steps for 3-oxa-6-sila-bicyclo[3,1,0]hexane based on this survey. One further pathway leading to butadiene + silanone was also included. Details of these additional calculations are given in the supporting information.

(33) From the 2,5-DHF $\cdot \mathrm{SiH}_{2}$ complex to TS4 $\Delta H^{\mathrm{o}}=+17 \mathrm{~kJ} \mathrm{~mol}^{-1}$ and $\Delta G^{\mathrm{o}}=+16 \mathrm{~kJ}$ $\mathrm{mol}^{-1}$ at $298 \mathrm{~K}$. Calculation shows that at $598 \mathrm{~K}, \Delta G^{\mathrm{o}}=+15 \mathrm{~kJ} \mathrm{~mol}^{-1}$ at $598 \mathrm{~K}$.

(34) Becerra, R.; Walsh, R., Gas-phase kinetic study of the silylene addition reaction to acetylene and acetylene-d2 over the temperature range 291-613 K. Int. J. Chem. Kinet. 1994, 26, 45-60.

(35) Al-Rubaiey, N.; Walsh, R., Gas-Phase Kinetic Study of the Prototype Silylene Addition Reaction $\mathrm{SiH}_{2}+\mathrm{C}_{2} \mathrm{H}_{4}$ over the Temperature Range 298-595 K. An Example of a Third-Body Mediated Association. J. Phys. Chem. 1994, 98, 53035309.

(36) Becerra, R.; Cannady, J. P.; Walsh, R., Gas-Phase Reaction of Silylene with Acetone: Direct Rate Studies, RRKM Modeling, and ab Initio Studies of the Potential Energy Surface. J. Phys. Chem. A 1999, 103, 4457-4464.

(37) Becerra, R.; Cannady, J. P.; Walsh, R., Silylene Does React with Carbon Monoxide: Some Gas-Phase Kinetic and Theoretical Studies. J. Phys. Chem. A 2001, 105, 1897-1903.

(38) Becerra, R.; Cannady, J. P.; Walsh, R., The gas-phase reaction of silylene with acetaldehyde Part 1. Direct rate studies, isotope effects, RRKM modelling and ab initio studies of the potential energy surface. Phys. Chem. Chem. Phys. 2001, 3, 2343-2351.

(39) Al-Rubaiey, N.; Becerra, R.; Walsh, R., A gas-phase kinetic study of the silylene addition reaction $\mathrm{SiH}_{2}+\mathrm{C}_{2} \mathrm{D}_{4}$ as a function of temperature and pressure: isotope effects and mechanistic complexities. Phys. Chem. Chem. Phys. 2002, 4, 50725078. 
(40) Becerra, R.; Cannady, J. P.; Walsh, R., Investigation of the Prototype Silylene Reaction, $\mathrm{SiH}_{2}+\mathrm{H}_{2} \mathrm{O}$ (and D2O): Time-Resolved Gas-Phase Kinetic Studies, Isotope Effects, RRKM Calculations, and Quantum Chemical Calculations of the Reaction Energy Surface. J. Phys. Chem. A 2003, 107, 11049-11056.

(41) Becerra, R.; Goldberg, N.; Cannady, J. P.; Almond, M. J.; Ogden, J. S.; Walsh, R., Experimental and Theoretical Evidence for Homogeneous Catalysis in the GasPhase Reaction of $\mathrm{SiH}_{2}$ with $\mathrm{H}_{2} \mathrm{O}$ (and $\mathrm{D}_{2} \mathrm{O}$ ): A Combined Kinetic and Quantum Chemical Study. J. Am. Chem. Soc. 2004, 126, 6816-6824.

(42) Becerra, R.; Cannady, J. P.; Walsh, R., Time-Resolved Gas-Phase Kinetic and Quantum Chemical Studies of Reactions of Silylene with Chlorine-Containing Species. 1. HCl. J. Phys. Chem. A 2004, 108, 3987-3993.

(43) Becerra, R.; Bowes, S-J.; Ogden, J. S.; Cannady, J. P.; Almond, M. J.; Walsh, R., Time-Resolved Gas-Phase Kinetic and Quantum Chemical Studies of the Reaction of Silylene with Nitric Oxide. J. Phys. Chem. A 2005, 109, 1071-1080.

(44) Becerra, R.; Bowes, S-J.; Ogden, J. S.; Cannady, J. P.; Adamovic, I.; Gordon, M. S.; Almond, M. J.; Walsh, R., Time-resolved gas-phase kinetic and quantum chemical studies of the reaction of silylene with oxygen. Phys. Chem. Chem. Phys. 2005, 7, 2900-2908.

(45) Becerra, R.; Cannady, J. P.; Walsh, R., Time-Resolved Gas-Phase Kinetic and Quantum Chemical Studies of Reactions of Silylene with Chlorine-Containing Species. 2. $\mathrm{CH}_{3} \mathrm{Cl}$. J. Phys. Chem. A 2006, 110, 6680-6686.

(46) Becerra, R.; Carpenter, I. W.; Gordon, M. S; Roskop, L.; Walsh, R., Gas phase kinetic and quantum chemical studies of the reactions of silylene with the methylsilanes. Absolute rate constants, temperature dependences, RRKM modelling and potential energy surfaces. Phys. Chem. Chem. Phys. 2007, 9, 2121-2129.

(47) Becerra, R.; Cannady, J. P.; Walsh, R., The Addition Reaction between Silylene and Ethyne: Further Isotope Studies, Pressure Dependence Studies, and Quantum Chemical Calculations. J. Phys. Chem. A 2008, 112, 8665-8677.

(48) Becerra, R.; Cannady, J. P.; Dormer, G.; Walsh, R., The gas-phase reaction between silylene and 2-butyne: kinetics, isotope studies, pressure dependence studies and quantum chemical calculations. Phys. Chem. Chem. Phys. 2009, 11, $5331-5344$. 
(49) Becerra, R.; Cannady, J. P.; Walsh, R., Time-Resolved Gas-Phase Kinetic, Quantum Chemical, and RRKM Studies of Reactions of Silylene with Alcohols. $J$. Phys. Chem. A 2011, 115, 4231-4240.

(50) Becerra, R.; Boganov, S. E.; Egorov, M. P.; Krilova, I. V.; Promyslov, V.M.; Walsh, R., Unusual Isotope Effect in the Reaction of Chlorosilylene with Trimethylsilane-1-d. Absolute Rate Studies and Quantum Chemical and RiceRamsperger-Kassel-Marcus Calculations Provide Strong Evidence for the Involvement of an Intermediate Complex. J. Am. Chem. Soc. 2012, 134, 1049310501.

(51) Becerra, R.; Cannady, J. P.; Goldberg, N.; Walsh, R., Reaction of silylene with sulfur dioxide: some gas-phase kinetic and theoretical studies. Phys. Chem. Chem. Phys. 2013, 15, 14748-14760.

(52) Klots, T. D.; Collier W. B., Vibrational assignment and analysis for 2,3dihydrofuran and 2,5-dihydrofuran. Spectrochim Acta A 1994, 50, 1725-1748.

(53) The quantum chemically calculated vibration wavenumbers were close but not identical to those estimated.

(54) Hippler, H.; Troe, J. in Advances in Gas Phase Photochemistry and Kinetics, Eds. M. N. R. Ashfold and J. E. Baggott, Royal Society of Chemistry: London, 1989, vol 2, chapter 5, p.209.

(55) Although the adjustment of $k^{\infty}$ values in principle affects the transition state parameters and modelling, these small changes make very little difference to the calculated pressure dependences.

(56) Baggott, J. E.; Blitz, M. A.; Frey, H.M.; Lightfoot, P. D.; Walsh, R., Absolute rate measurements for some gas-phase addition reactions of dimethylsilylene . J. Chem. Soc., Faraday Trans. 2 1988, 84, 515-526.

(57) The same value has been assumed as for $\mathrm{SiH}_{2}+\mathrm{THF}^{11}$, but (unfortunately) it was erroneously reported there as $5.2 \times 10^{-10} \mathrm{~cm}^{3}$ molecule $^{-1} \mathrm{~s}^{-1}$ (in Table 8). The reported collision efficiency of $45 \%$ was, however, correct.

(58) Becerra, R.; Walsh, R., Time-resolved gas-phase kinetic study of the reaction of germylene with propene over the temperature range $293-415 \mathrm{~K}$ : the thermal stabilities of germiranes. J. Organometal. Chem. 2001, 636, 49-55.

(59) Alexander, U. N.; King, K. D.; Lawrance, W. D., Pressure and temperature dependence of the gas-phase reaction of silylene with dimethyl ether. Phys. Chem. Chem. Phys. 2001, 3, 3085-3094. 
(60) Apeloig, Y.; Sklenak, $\mathrm{S}$., On the possible formation of $\mathrm{Si}=\mathrm{O}, \mathrm{Si}=\mathrm{S}$, and $\mathrm{Si}=\mathrm{Se}$ double bonds via the reaction of silylenes with oxirane, thiirane, and selenirane, respectively. An ab initio theoretical study. Can. J. Chem. 2000, 78, 1496-1510.

(61) Su, M-D., Theoretical Study of Silylene Substituent Effects on the Abstraction Reactions with Oxirane and Thiirane. J. Am. Chem. Soc. 2002, 124, 12335-12342.

(62) Heaven, M. W.; Metha, G. F.; Buntine, M. A., Reaction Pathways of Singlet Silylene and Singlet Germylene with Water, Methanol, Ethanol, Dimethyl Ether, and Trifluoromethanol: An ab Initio Molecular Orbital Study. J. Phys. Chem. A 2001, 105, 1185-1196.

(63) Boatz, J. A.; Gordon, M. S., Theoretical studies of three-membered ring compounds $\mathrm{Y}_{2} \mathrm{H}_{4} \mathrm{X}\left(\mathrm{Y}=\mathrm{C}, \mathrm{Si} ; \mathrm{X}=\mathrm{CH}_{2}, \mathrm{NH}, \mathrm{O}, \mathrm{SiH}_{2}, \mathrm{PH}, \mathrm{S}\right)$. J. Phys. Chem., 1989, 93, 3025-3029.

(64) Horner, D. A.; Grev, R. S.; Schaefer, H. F. III, Three-membered rings of carbon, silicon, and germanium. An analysis of thermodynamic stability to fragmentation. J. Am. Chem. Soc., 1992, 114, 2093-2098.

(65) Skancke, P. N.; Hrovat, D. A.; Borden, W. T., Ab Initio Calculations on the Preferred Mode of Ring Opening in Silacyclopropane. J. Am. Chem. Soc., 1997, $119,8012-8014$.

(66) Benson, S. W. Thermochemical Kinetics, $2^{\text {nd }}$ ed.; Wiley: New York, 1976. 
Table 1. Experimental second order rate coefficients ${ }^{a}$ at 10 Torr and infinite pressure for $\mathrm{SiH}_{2}+2,5-\mathrm{DHF}$ as a function of temperature

\begin{tabular}{ccc}
\hline$T / \mathrm{K}$ & $k(10$ Torr $)$ & $k^{\infty}$ \\
\hline 296 & $2.170 \pm 0.063$ & $4.0 \pm 0.4$ \\
339 & $1.677 \pm 0.048$ & $3.8 \pm 0.4$ \\
404 & $0.961 \pm 0.046$ & $3.4 \pm 0.4$ \\
476 & $0.591 \pm 0.036$ & $2.6 \pm 0.5$ \\
${ }^{\mathrm{a} U n i t s: ~} 10^{-10} \mathrm{~cm}^{3}$ molecule $\mathrm{s}^{-1}$ & \\
\hline
\end{tabular}

Table 2. $\mathrm{G3}^{a}$ calculated total enthalpies, $H /$ hartree, relative enthalpies, $\Delta H_{\text {rel }} / \mathbf{k J}$ $\mathrm{mol}^{-1}$ and relative free energies, $\Delta G_{\mathrm{rel}} / \mathrm{kJ} \mathrm{mol}^{-1}$ for stationary points of interest on the $\mathrm{C}_{4} \mathrm{H}_{8} \mathrm{SiO}$ energy surface

\begin{tabular}{|c|c|c|c|}
\hline Species & $H(298 \mathrm{~K}) / \mathrm{ha}$ & $\Delta H_{\mathrm{rel}} / \mathrm{kJ} \mathrm{mol}^{-1}$ & $\Delta G_{\mathrm{rel}} / \mathrm{kJ} \mathrm{mol}^{-1}$ \\
\hline $2,5-\mathrm{DHF}+\mathrm{SiH}_{2}$ & -521.483466 & 0 & 0 \\
\hline 2,5-DHF $\cdot \cdot \mathrm{SiH}_{2}$ complex & -521.515431 & -84 & -46 \\
\hline 3-oxa-6-sila-bicyclo[3,1,0]hexane-syn & -521.555392 & -189 & -145 \\
\hline 3-oxa-6-sila-bicyclo[3,1,0]hexane-anti & $-521.550289^{b}$ & -175 & -124 \\
\hline 2-sila-3,6-dihydropyran & -521.631228 & -388 & -340 \\
\hline 3 -vinylsiloxetane & -521.597919 & -300 & -257 \\
\hline cis-but-2-enoxysilylene & -521.570738 & -229 & -193 \\
\hline but-3-enoxysilylene & -521.570555 & -229 & -192 \\
\hline $1,3-\mathrm{C}_{4} \mathrm{H}_{6} \cdot{ }^{\circ} \mathrm{OSiH}_{2}$ complex & -521.553292 & -183 & -174 \\
\hline $1,3-\mathrm{C}_{4} \mathrm{H}_{6}+\mathrm{OSiH}_{2}$ & -521.550134 & -190 & -197 \\
\hline vinyloxirane $+\mathrm{SiH}_{2}$ & -521.452099 & +82 & +78 \\
\hline vinyloxirane $\cdot \mathrm{SiH}_{2}$ complex & -521.480787 & +7 & +44 \\
\hline TS1 & -521.471777 & +31 & +76 \\
\hline TS2 & -521.446269 & +98 & +154 \\
\hline TS3 & -521.463016 & +54 & +101 \\
\hline TS4 & -521.509139 & -67 & -30 \\
\hline TS5 & -521.562723 & -208 & -161 \\
\hline TS6 & -521.547744 & -169 & -117 \\
\hline TS7 & -521.539210 & -146 & -94 \\
\hline TS8a & -521.522863 & -103 & -55 \\
\hline TS8b & -521.520834 & -98 & -50 \\
\hline TS9 & -521.443195 & +106 & +150 \\
\hline
\end{tabular}


Table 3. Estimated rate coefficients $\left(k^{\infty} / 10^{-10} \mathrm{~cm}^{3}\right.$ molecule $\left.\mathrm{s}^{-1}\right)$ for the $\pi$ - and $O$-additions of $\mathrm{SiH}_{2}+2,5-\mathrm{DHF}$

\begin{tabular}{|c|c|c|c|c|c|c|c|}
\hline Temp/K & $\log \left(k^{\infty \mathrm{a}}\right)$ & $k^{\infty}$ & $k^{\infty}\left(\mathrm{i}-\mathrm{C}_{4} \mathrm{H}_{8}\right)$ & $k^{\infty}(\mathrm{THF})$ & $\begin{array}{l}k^{\infty}\left(\mathrm{i}-\mathrm{C}_{4} \mathrm{H}_{8}\right) \\
+k^{\infty}(\mathrm{THF})\end{array}$ & $k^{\infty}(\pi)^{b, c}$ & $k^{\infty}(\mathrm{O})^{b, c}$ \\
\hline 296 & -9.40 & 4.0 & 3.2 & 2.8 & 6.0 & (2.12) 1.70 & 2.66 (1.88) \\
\hline 339 & -9.42 & 3.8 & 3.0 & 2.0 & 5.0 & 1.60 (2.28) & 2.20 \\
\hline 404 & -9.47 & 3.4 & 2.5 & 1.5 & 4.0 & (2.14) 1.10 & 2.29 (1.26) \\
\hline 476 & -9.58 & 2.6 & 2.3 & 1.1 & 3.4 & 1.00 (1.77) & (0.83) 1.60 \\
\hline 598 & -9.70 & 2.0 & 1.9 & 0.82 & 2.7 & (1.40) 0.88 & (0.60) 1.12 \\
\hline
\end{tabular}

Table 4. Entropy changes and decomposition $A$ factors for the $\pi$ - and $O$-adducts of $\mathrm{SiH}_{2}+2,5-\mathrm{DHF}$

\begin{tabular}{ccccc}
\hline Temp $/ \mathrm{K}$ & $\Delta S^{\mathrm{o}}(\pi) / \mathrm{J} \mathrm{K}^{-1} \mathrm{~mol}^{-1}$ & $\log \left(A_{-\mathrm{a}}(\pi) / \mathrm{s}^{-1}\right)$ & $\Delta S^{\mathrm{O}}(\mathrm{O}) / \mathrm{J} \mathrm{K}^{-1} \mathrm{~mol}^{-1}$ & $\log \left(A_{-\mathrm{a}}(\mathrm{O}) / \mathrm{s}^{-1}\right)$ \\
\hline 296 & 159.5 & 17.30 & 153.8 & 16.31 \\
339 & 159.4 & 17.26 & 153.4 & 16.24 \\
404 & 159.2 & 17.15 & 152.9 & 16.12 \\
476 & 157.8 & 17.01 & 152.4 & 16.02 \\
598 & 155.5 & 16.79 & 151.4 & 15.88 \\
\hline
\end{tabular}


Table 5. Molecular and transition state parameters for RRKM calculations for decomposition of the $\mathrm{SiH}_{2} \cdot$ DHF $\pi$-complex ${ }^{\mathrm{a}}$ at $296 \mathrm{~K}$

\begin{tabular}{|c|c|c|}
\hline & $\pi$ complex & $\mathrm{TS}(\pi$-complex $)$ \\
\hline \multirow[t]{24}{*}{$\tilde{v} / \mathrm{cm}^{-1}$} & $2948(6)$ & $2948(6)$ \\
\hline & $2135(2)$ & $2135(2)$ \\
\hline & $1484(2)$ & $1484(2)$ \\
\hline & $1335(2)$ & $1335(2)$ \\
\hline & $1225(2)$ & $1225(2)$ \\
\hline & $1182(2)$ & $1182(2)$ \\
\hline & 1094(1) & 1094(1) \\
\hline & $1032(2)$ & $1032(2)$ \\
\hline & 1001(1) & $1001(1)$ \\
\hline & $955(1)$ & $1500(1)$ \\
\hline & $935(1)$ & $935(1)$ \\
\hline & $908(1)$ & $908(1)$ \\
\hline & $900(1)$ & $900(1)$ \\
\hline & $894(1)$ & $894(1)$ \\
\hline & $875(1)$ & $782(1)$ \\
\hline & $782(1)$ & $757(1)$ \\
\hline & $757(1)$ & $667(1)$ \\
\hline & $675(1)$ & $389(1)$ \\
\hline & $667(1)$ & $187(1)$ \\
\hline & $620(2)$ & $150(1)$ \\
\hline & $473(1)$ & $80(1)$ \\
\hline & $392(1)$ & $60(1)$ \\
\hline & $389(1)$ & $40(1)$ \\
\hline & $187(1)$ & $35(1)$ \\
\hline reaction coordinate $/ \mathrm{cm}^{-1}$ & \multicolumn{2}{|l|}{875} \\
\hline path degeneracy & \multicolumn{2}{|l|}{1} \\
\hline$E_{\mathrm{o}}$ (critical energy) $/ \mathrm{kJ} \mathrm{mol}^{-1}$ & \multicolumn{2}{|l|}{148} \\
\hline $\begin{array}{l}\text { Collision number }\left(\text { in } \mathrm{SF}_{6} \text { ) }\right. \\
Z_{\mathrm{LJ}} / 10^{-10} \mathrm{~cm}^{3} \text { molecule } \mathrm{s}^{-1}\end{array}$ & \multicolumn{2}{|l|}{5.17} \\
\hline \multicolumn{3}{|c|}{ a 3 -oxa-6-sila-bicyclo[3,1,0]hexane } \\
\hline
\end{tabular}


Table 6. Molecular and transition state parameters for RRKM calculations for decomposition of the $\mathrm{SiH}_{2} \cdot$ DHF O-complex at $296 \mathrm{~K}$

\begin{tabular}{|c|c|c|}
\hline & O-complex & $\mathrm{TS}(\mathrm{O}$-complex $)$ \\
\hline \multirow[t]{25}{*}{$\tilde{\boldsymbol{v}} / \mathrm{cm}^{-1}$} & $2948(6)$ & $2948(6)$ \\
\hline & $1912(2)$ & $2135(2)$ \\
\hline & $1623(1)$ & $1623(1)$ \\
\hline & $1484(2)$ & $1484(2)$ \\
\hline & $1335(2)$ & $1335(2)$ \\
\hline & $1225(2)$ & $1225(2)$ \\
\hline & $1182(2)$ & $1182(2)$ \\
\hline & 1094(1) & 1094(1) \\
\hline & $1032(2)$ & $1032(2)$ \\
\hline & $1001(1)$ & $1001(1)$ \\
\hline & $942(1)$ & $942(1)$ \\
\hline & $908(1)$ & $908(1)$ \\
\hline & $900(1)$ & $900(1)$ \\
\hline & $894(1)$ & 894(1) \\
\hline & $782(1)$ & $782(1)$ \\
\hline & $757(1)$ & $757(1)$ \\
\hline & $725(1)$ & $667(1)$ \\
\hline & $667(1)$ & $389(1)$ \\
\hline & $620(1)$ & $187(1)$ \\
\hline & $389(1)$ & $110(1)$ \\
\hline & $236(1)$ & $40(1)$ \\
\hline & $187(1)$ & $30(1)$ \\
\hline & $134(1)$ & $15(1)$ \\
\hline & $77(1)$ & $13(1)$ \\
\hline & $35(1)$ & - \\
\hline reaction coordinate $/ \mathrm{cm}^{-1}$ & 725 & \\
\hline path degeneracy & 1 & \\
\hline$E_{\mathrm{o}}$ (critical energy) $/ \mathrm{kJ} \mathrm{mol}^{-1}$ & 80 & \\
\hline $\begin{array}{l}\text { Collision number (in } \mathrm{SF}_{6} \text { ) } \\
Z_{\mathrm{LJ}} / 10^{-10} \mathrm{~cm}^{3} \text { molecule } \mathrm{s}^{-1}\end{array}$ & 5.17 & \\
\hline
\end{tabular}


Table 7. Transition state adjusted wavenumbers and collision numbers at each temperature for decomposition of the $\mathrm{SiH}_{2} \cdot \mathrm{DHF} \pi$-complex ${ }^{\mathrm{a}}$

\begin{tabular}{|c|c|c|c|c|c|}
\hline & & & $\mathrm{T} / \mathrm{K}$ & & \\
\hline & 296 & 339 & 404 & 476 & 598 \\
\hline wavenumber $/ \mathrm{cm}^{-1}$ & 1500 & 1500 & 1500 & 1500 & 1500 \\
\hline & 150 & 100 & 140 & 120 & 200 \\
\hline & 80 & 75 & 100 & 95 & 100 \\
\hline & 60 & 69 & 80 & 90 & 90 \\
\hline & 40 & 65 & 61 & 70 & 80 \\
\hline & 35 & 45 & 40 & 65 & 67 \\
\hline $\begin{array}{l}\text { Collision number in } \mathrm{SF}_{6} \\
\mathrm{Z}_{\mathrm{LJ}} / 10^{-10} \mathrm{~cm}^{3} \text { molecule } \mathrm{s}^{-1}\end{array}$ & 5.17 & 5.28 & 5.40 & 5.47 & 5.84 \\
\hline
\end{tabular}

Table 8. Transition state adjusted wavenumbers and collision numbers at each temperature for decomposition of the $\mathrm{SiH}_{2} \cdot$ DHF O-complex

\begin{tabular}{|c|c|c|c|c|c|}
\hline & & & $\mathrm{T} / \mathrm{K}$ & & \\
\hline \multirow{6}{*}{ wavenumber $/ \mathrm{cm}^{-1}$} & 296 & 339 & 404 & 476 & 598 \\
\hline & 110 & 100 & 90 & 110 & 208 \\
\hline & 40 & 40 & 50 & 80 & 50 \\
\hline & 30 & 30 & 40 & 30 & 40 \\
\hline & 15 & 20 & 20 & 20 & 20 \\
\hline & 13 & 15 & 15 & 15 & 15 \\
\hline $\begin{array}{l}\text { Collision number in } \mathrm{SF}_{6}, \\
\mathrm{Z}_{\mathrm{LJ}} / 10^{-10} \mathrm{~cm}^{3} \text { molecule }{ }^{-1} \mathrm{~s}^{-1}\end{array}$ & 5.17 & 5.28 & 5.40 & 5.47 & 5.84 \\
\hline
\end{tabular}

Table 9. Comparison of Arrhenius parameters for elementary silylene reactions with alkenes and alkynes ${ }^{a}$

\begin{tabular}{lccc}
\hline Reaction & $\log \left(A / \mathrm{cm}^{3}\right.$ molecule $\left.^{-1} \mathrm{~s}^{-1}\right)$ & $E_{\mathrm{a}} / \mathrm{kJ} \mathrm{mol}^{-1}$ & Ref \\
\hline $\mathrm{SiH}_{2}+\mathrm{C}_{2} \mathrm{H}_{4}$ & $-9.97 \pm 0.03$ & $-2.90 \pm 0.20$ & 56 \\
$\mathrm{SiH}_{2}+\mathrm{C}_{3} \mathrm{H}_{6}$ & $-9.79 \pm 0.05$ & $-1.90 \pm 0.34$ & 22 \\
$\mathrm{SiH}_{2}+\mathrm{i}-\mathrm{C}_{4} \mathrm{H}_{8}$ & $-9.91 \pm 0.04$ & $-2.45 \pm 0.30$ & 22 \\
$\mathrm{SiH}_{2}+2,5-\mathrm{DHF}$ & $-10.37 \pm 0.12^{\mathrm{b}}$ & $-3.49 \pm 0.92^{\mathrm{b}}$ & This work \\
$\mathrm{SiH}_{2}+\mathrm{C}_{2} \mathrm{H}_{2}$ & $-9.99 \pm 0.03$ & $-3.30 \pm 0.20$ & 34 \\
& & \\
& & \\
${ }^{a}$ High pressure limiting values & \multicolumn{3}{c}{$98 \%$ confidence limits } \\
\hline
\end{tabular}


Table 10. Comparison of Arrhenius parameters for elementary silylene reactions with ethers ${ }^{a}$

\begin{tabular}{lccc}
\hline Reaction & $\log \left(A / \mathrm{cm}^{3} \mathrm{molecule}^{-1} \mathrm{~s}^{-1}\right)$ & $E_{\mathrm{a}} / \mathrm{kJ} \mathrm{mol}^{-1}$ & Ref \\
\hline $\mathrm{SiH}_{2}+$ oxirane & $-11.03 \pm 0.07$ & $-5.70 \pm 0.51$ & 23 \\
$\mathrm{SiH}_{2}+$ oxetane & $-11.17 \pm 0.11$ & $-9.04 \pm 0.78$ & 23 \\
$\mathrm{SiH}_{2}+\mathrm{THF}$ & $-10.59 \pm 0.10$ & $-5.76 \pm 0.65$ & 23 \\
$\mathrm{SiH}_{2}+2,5-\mathrm{DHF}$ & $-10.24 \pm 0.26^{\mathrm{b}}$ & $-3.95 \pm 1.86^{\mathrm{b}}$ & This work \\
$\mathrm{SiH}_{2}+\mathrm{Me}_{2} \mathrm{O}$ & $-7.60 \pm 0.4$ & $+9.30 \pm 2.8$ & 59 \\
${ }^{a} \mathrm{High}$ pressure limiting values & ${ }^{\mathrm{b}} 95 \%$ confidence limits & \\
\hline
\end{tabular}

Table 11. Comparison of calculated and experimental enthalpy changes for formation of O-donor complexes

\begin{tabular}{|c|c|c|}
\hline \multirow{2}{*}{ Species } & \multicolumn{2}{|c|}{$\Delta H^{\mathrm{o}} / \mathrm{kJ} \mathrm{mol}^{-1}$} \\
\hline & Calculated & Expt \\
\hline 2,5-DHF $\cdot \mathrm{SiH}_{2}$ & $-84^{\mathrm{a}}$ & $-92 \pm 10^{\mathrm{b}}$ \\
\hline $\mathrm{THF} \cdot \mathrm{SiH}_{2}$ & $-94^{\mathrm{c}}$ & $-92 \pm 10^{d}$ \\
\hline Oxetane $\cdot \mathrm{SiH}_{2}$ & $-99^{\mathrm{c}}$ & - \\
\hline Oxirane $\cdot \mathrm{SiH}_{2}$ & $-84^{\mathrm{e}},-67^{\mathrm{f}},-79^{\mathrm{c}},-62^{\mathrm{g}}$ & - \\
\hline $\mathrm{Me}_{2} \mathrm{O} \cdot \mathrm{SiH}_{2}$ & $-84^{\mathrm{a}},-83^{\mathrm{h}},-84^{\mathrm{i}}$ & $-88^{j}$ \\
\hline \multicolumn{3}{|c|}{$\begin{array}{l}{ }^{\mathrm{a}} \mathrm{G} 3 \text {, this work }{ }^{\mathrm{b}} \text { From RRKM fit, this work }{ }^{\mathrm{c}} \mathrm{G} 3 \text { level Ref } 23{ }^{\mathrm{d}} \text { From RRKM fit, } \\
\text { Ref } 23{ }^{\mathrm{e}} \mathrm{MP} 2 / 6-31 \mathrm{G}^{* *}, \Delta E^{\mathrm{o}}(0 \mathrm{~K}) \text {, Ref } 60{ }^{\mathrm{f}} \text { B3LYP/6-311G(d), } \Delta E^{\mathrm{o}}(0 \mathrm{~K}) \text {, Ref } 61 \\
{ }_{\mathrm{g}} \text { B3LYP/6-311+G(d,p), Ref } 16{ }^{\mathrm{h}} \mathrm{MP} 2 / 6-311+\mathrm{G}^{* *}, \Delta E^{\mathrm{o}}(0 \mathrm{~K}) \text {, Ref } 59 \\
{ }^{\mathrm{i}} \mathrm{MP} 2 / 6-311+\mathrm{G}(\mathrm{d}, \mathrm{p}), \Delta E^{\mathrm{o}}(0 \mathrm{~K}) \text {, Ref } 62{ }^{\mathrm{j}} \text { From RRKM fit, Ref } 59\end{array}$} \\
\hline
\end{tabular}

Table 12. Comparison of calculated and experimental enthalpy changes for formation of siliranes ( $\pi$ complexes)

\begin{tabular}{|c|c|c|}
\hline \multirow{2}{*}{ Species } & \multicolumn{2}{|c|}{$\Delta H^{\mathrm{o}} / \mathrm{kJ} \mathrm{mol}^{-1}$} \\
\hline & Calculated & Expt \\
\hline 3-oxa-6-sila-bicyclo[3,1,0]hexane-syn & $-189^{\mathrm{a}}$ & $-164 \pm 10^{b}$ \\
\hline 3-oxa-6-sila-bicyclo[3,1,0]hexane-anti & $-175^{\mathrm{a}}$ & $-164 \pm 10^{b}$ \\
\hline Silirane & $-203^{\mathrm{c}},-187^{\mathrm{d}},-181^{\mathrm{e}},-169^{\mathrm{f}}$ & $-201^{\mathrm{g}}$ \\
\hline 2-methylsilirane & $-173^{\mathrm{c}}$ & $-176^{\mathrm{g}}$ \\
\hline 2,2-dimethylsilirane & $-169^{c}$ & $-165^{\mathrm{g}}$ \\
\hline 2,3-dimethylsilirane & $-169^{\mathrm{a}}$ & - \\
\hline${ }^{\mathrm{a}} \mathrm{G} 3$, this work $\quad{ }^{\mathrm{b}}$ From RRK & \multicolumn{2}{|c|}{${ }^{\mathrm{b}}$ From RRKM fit, this work $\quad{ }^{\mathrm{c}}$ G2 level, Ref 22} \\
\hline${ }^{\mathrm{d}} \mathrm{MP} 2 / 6-31 \mathrm{G}(\mathrm{d}), \Delta H^{\mathrm{o}}(0 \mathrm{~K}), \operatorname{Ref} 63$ & \multicolumn{2}{|c|}{${ }^{\mathrm{e}} \mathrm{DZ}+\mathrm{d}$ CCSD, $\Delta H^{\mathrm{o}}(0 \mathrm{~K}), \operatorname{Ref} 64$} \\
\hline${ }^{\mathrm{f}}(12 / 12) \mathrm{CASPT} 2 \mathrm{~N}, \Delta E_{0}(0 \mathrm{~K}), \operatorname{Ref} 65$ & \multicolumn{2}{|c|}{${ }^{\mathrm{g}}$ From RRKM fits, Ref 22} \\
\hline
\end{tabular}


Table 13. $\mathrm{G3}^{a}$ calculated total enthalpies, $H /$ hartree, and relative enthalpies, $\Delta H_{\text {rel }} / \mathrm{kJ} \mathrm{mol}^{-1}$, for stationary points of interest on the $\mathrm{C}_{2} \mathrm{H}_{8} \mathrm{SiO}$ and $\mathrm{C}_{4} \mathrm{H}_{10} \mathrm{Si}$ energy surfaces

\begin{tabular}{|c|c|c|}
\hline Species & $H(298 \mathrm{~K}) / \mathrm{ha}$ & $\Delta H_{\mathrm{rel}} / \mathrm{kJ} \mathrm{mol}^{-1}$ \\
\hline $\mathrm{Me}_{2} \mathrm{O}+\mathrm{SiH}_{2}$ & -445.334282 & 0 \\
\hline $\mathrm{Me}_{2} \mathrm{O} \cdot \mathrm{SiH}_{2}$ complex & -445.366390 & -84 \\
\hline $\mathrm{MeOSiH}_{2} \mathrm{Me}$ & -445.485201 & -396 \\
\hline $\mathrm{MeOSiH}+\mathrm{CH}_{4}$ & -445.421807 & -230 \\
\hline $\mathrm{MeOSiH}_{2}+\mathrm{Me}$ & -445.340306 & -16 \\
\hline TS1r & -445.305926 & +74 \\
\hline TS2r & $-445.363036^{\mathrm{b}}$ & -75 \\
\hline
\end{tabular}




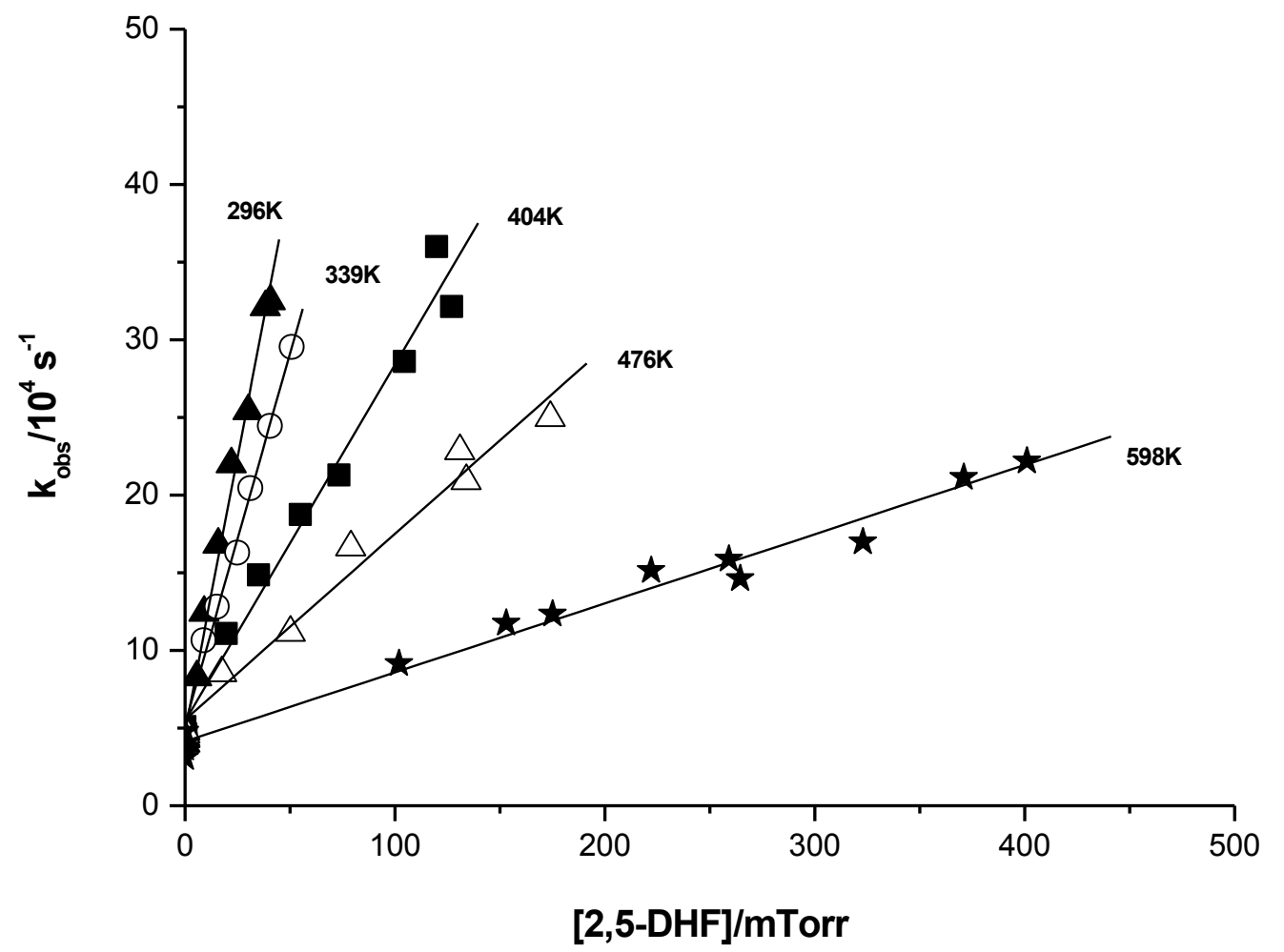

Figure 1. Second order plots for the reaction of $\mathrm{SiH}_{2}$ with 2,5-DHF at total pressures of 10 Torr (added $\mathrm{SF}_{6}$ ) and various temperatures (indicated). Different symbols are used at each temperature. 


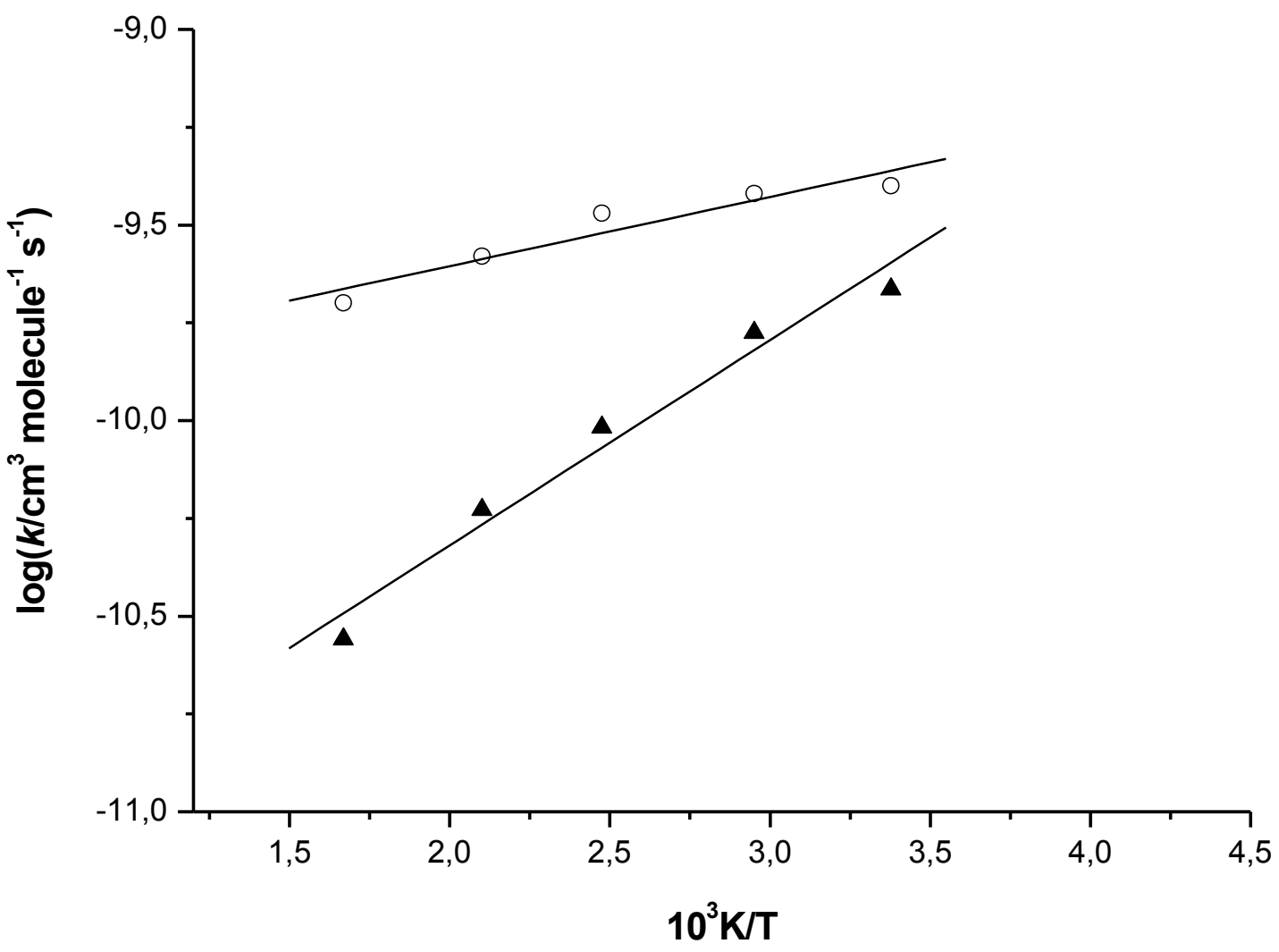

Figure 2. Arrhenius plots of second order rate coefficients for $\mathrm{SiH}_{2}+2,5-\mathrm{DHF}$ at $10 \mathrm{Torr}$ (added $\mathrm{SF}_{6}$ ); $\boldsymbol{\Lambda}$, and infinite pressure; $\bigcirc$. 


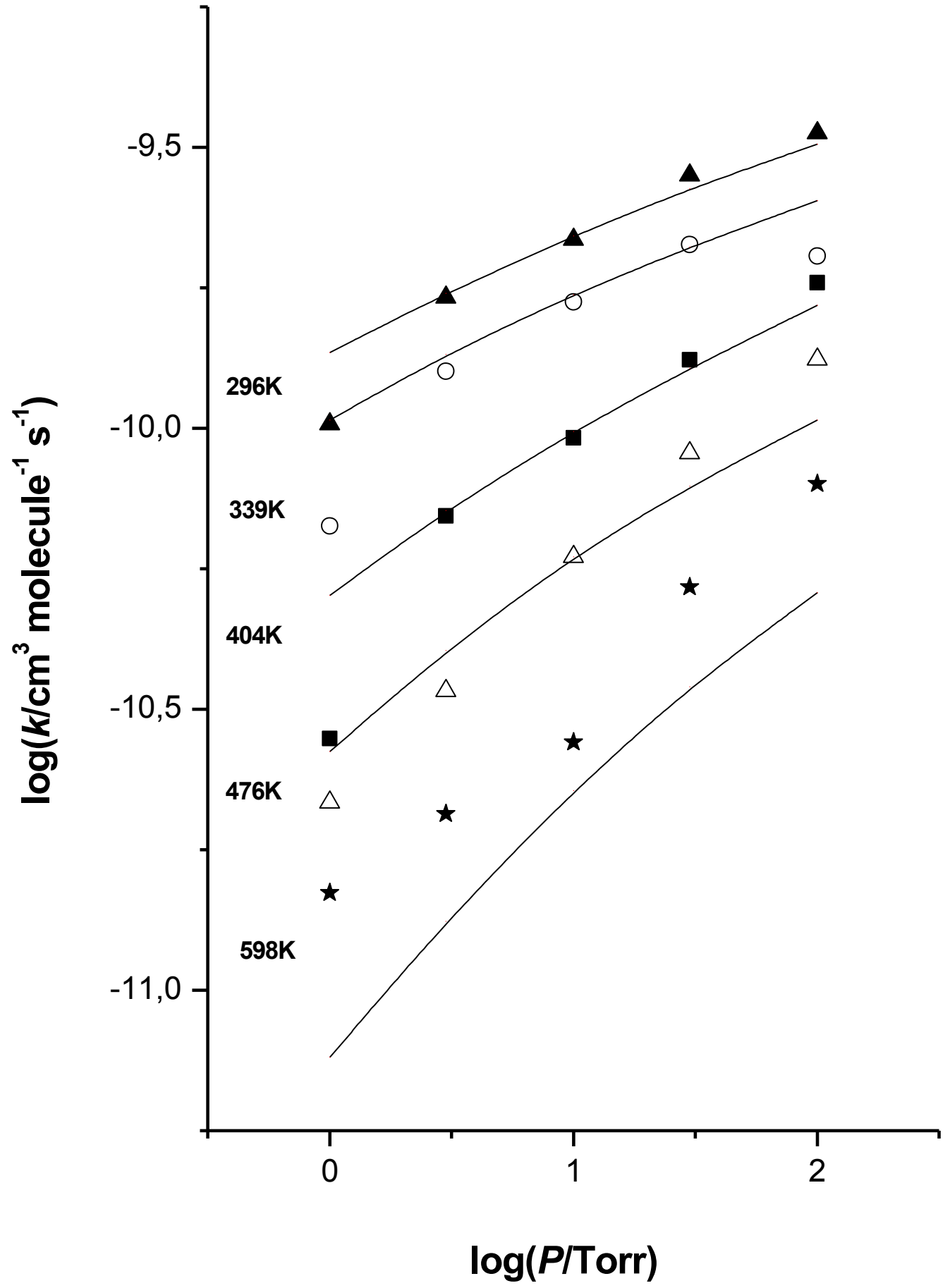

Figure 3. Pressure dependence of second order rate coefficients for $\mathrm{SiH}_{2}+2,5-\mathrm{DHF}$ at different temperatures/K: $\mathbf{\Delta}, 296 ; \circ, 339 ; \mathbf{\square}, 404 ; \triangle, 476 ; \star, 598$. Solid lines are RRKM theoretical fits at each temperature. 